\title{
AYUDA EXTERNA Y MAS POBREZA EN EL SALVADOR
}

\author{
Sonia Ivett Sánchez 1
}

7 presente trabajo busca destacar la importancia de la ayuda externa en el desarrollo social de El Salvador durante el período 1973-1992. Se parte del hecho que la ayuda externa dirigida al sector social, proveniente de fuentes bilaterales y/o multilaterales, no logró impactar de manera decisiva los indicadores de pobreza.

Se comienza haciendo un análisis de la importancia del sector social respecto de sus indicadores más relevantes: producto interno bruto, presupuesto nacional y gasto público destinado al desarrollo social. Luego, se describe la evolución de indicadores sociales tales como, niveles de pobreza, acceso a la educación, salud, con el propósito de inferir si los cuantiosos flujos de ayuda externa modificaron positivamente los mismos.

\section{Introducción}

耳 $n$ su discurso inagural de toma de poseción, el Presidente Cal¿derón Sol enfatizó la necesidad que tiene el país de resolver los agudos problemas en materia social como ingrediente necesario para garantizar la estabilidad social y premisa para consolidar el crecimiento económico. En el período presidencial anterior, también se dijo que "los únicos privilegiados del gobierno serían los 
más pobres de los pobres".

Ha sido reiterativo, a lo largo de las últimas tres décadas, la intención de los diversos gobiemos de atender a las amplias mayorías de salvadoreños a través de los servicios sociales. Nunca como ahora la política social ha sido la abanderada como pilar fundamental de las propuestas de gobierno. De hecho, la temática ha cobrado preponderancia en foros mundiales y eventos internacionales de gran trascendencia.

Pasaremos a analizar qué tanto se reflejan las prioridades sociales en los presupuestos gubernamentales desde 1973 a 1992 y cómo se inserta, en este marco, la ayuda externa dirigida al sector social.

\section{Importancia del sector social en el gasto público}

La evolución del gasto social en El Salvador muestra un franco público o desagregado por cada uno de los sectores sociales. En 1973, el gasto público destinado al desarrollo social representaba el $44.21 \%$, en 1992 esa proporción había descendido a $24.21 \%$. Tal disminución parece acentuarse en cada uno de los años que comprenden el período de análisis; esa tendencia se torna más evidente a partir de 1980 como resultado de la reorientación del gasto público hacia sectores más prioritarios.

La disminución del gasto social fue posible, según las cifras disponibles, gracias a la contracción visible del gasto destinado a los sectores sociales de mayor importancia, esto es, educación y salud. El período de guerra, no obstante, sólo parece agudizar la tendencia que ya era evidente en la década de los setenta.

Los gastos en salud y educción se mantiuvieron porcentualmente constantes respecto al PIB en un período bonancible y de pre-guerra (1973-1979). En los años ochenta hay una tendencia clara a la disminución, sobre todo en el sector de educación. El sector salud se mantiene bastante estable, quizá por la creciente demanda en los servicios de salud que se generaron durante el período de la guerra.

En relación al sector educación, El Salvador es uno de los países que gastan menos en ese rubro en América Latina, apenas el 
$1.5 \%$ en relación al PIB en 19922 . El sector de salud refleja un comportamiento similar, en 1993, apenas representaba el $1 \%$ del gasto en relación al PIB. ${ }^{3}$ Obviamente es de esperar que si el gasto social, en los sectores de salud y educación se mantuvo constante en relación al PIB durante los años setenta y disminuyó durante los ochenta, el gasto sectorial en relación al presupuesto nacional también tuvo una baja sustancial.

El gasto en salud como proporción del gasto público cae de $8.86 \%$ en 1974, hasta $6.1 \%$ en 1992 y en educación hay una caída global de $21.71 \%$ a tan solo $12.28 \%$ respectivamente.

La caída pronunciada de la participación de los sectores sociales de mayor importancia: educación y salud, como proporción del gasto público y como proporción del PIB, refleja -sin duda alguna- los cambios de prioridad de parte del Estado en el período estudiado. Ambos casos dejan evidencia de que la tendencia fue a la pérdida de importancia en esas carteras de estado. Esa evidencia también implica un cambio en la orientación del gasto público, particularmente en la década de los ochenta en donde se podría presumir que la importancia relativa del gasto público se orientó a la defensa. 4

El Cuadro $\mathrm{N}^{\circ} 2$ presenta algunas relaciones que muestran la importancia del gasto social respecto al presupuesto nacional. El gasto público promedio, en relación al PIB, en todo el período, (PN/PIB) fue equivalente al $16.9 \%$. Por su lado, el gasto público destinado al desarrollo social relacionado con el PIB (GPDS/PIB), representó el $4.39 \%$ en promedio entre 1973 y 1992; y, el gasto en desarrollo social en relación al presupuesto nacional (GPDS/PN) fue del $\mathbf{2 5 . 9 8 \%}$. Si se observan las tendencias en las relaciones citadas, según los diversos períodos, es fácil derivar la precariedad que va cobrando el gasto social.

Es importante señalar que el presupuesto nacional tendió a crecer, es más, en solo 3 años de la década de los noventa se tiene un monto casi equivalente al de 7 años en la década de los setenta. Sin embargo, la orientación del gasto refleja una pérdida de importancia para el sector social, dado que el gasto social en los 90 representa la mitad del valor del período 1970-79. 
Durante la década de los ochenta, el gasto público (PN) casi se triplicó, mientras que el gasto social (GPDS) creció más lentamente.

En los primeros tres años de los 90 parece iniciarse una reactivación del gasto social, aunque cabe advertir que el gasto público no recobra los niveles de principios de los años 70 . En suma, en términos del gasto doméstico, el sector social no fue el prioritario en los años estudiados. Los datos y las tendencias corroboran que el gasto público destinado al área social proveniente de fuentes domésticas, ha ido perdiendo prioridad en los años analizados, con ello se puede afirmar que los recursos internos destinados al desarrollo social han tendido a disminuir en todo el período.

Precisamene porque el gasto doméstico no fue destinado, en su mayoría, a atender los asuntos sociales es que se presume que la ayuda externa para dicha área fue un importante mecanismo orientado a amortiguar la previsible caída de bienestar de la mayoría de salvadoreños, quienes además de no haberse beneficiado del progreso económico de los años setenta, tuvieron que sobrellevar una guerra en los ochenta y más aún, tuvieron que soportar el impacto recesivo de las políticas de ajuste estuctural en los noventa.

Es en este marco que se inserta la ayuda externa como un mecanismo importante que contribuye a disminuir el deterioro previsible en la situación de pobreza y extrema pobreza que vive la mayoría de la población salvadoreña.

\section{Ayuda externa global y su peso en relación al sector social}

L

a ayuda externa total destinada a El Salvador desde 1973 a 1992 ha crecido al rededor de 35 veces, pasa de 7.7 a 278.5 millones de dólares respectivamente. El total de ayuda externa recibida por el país durante esos 20 años es equivalente a 4,920.7 millones de dólares (Cuadro $N^{\circ} 3$ ). En el período 1973-79 el porcentaje acumulado asciende a un modesto $8.3 \%$ del total de la ayuda. En el período 1980-89 se eleva más de 9 veces, llegando a $76.9 \%$ y en sólo 3 años en los noventa asciende a $14.7 \%$. Este comportamiento indica que la ayuda externa dirigida a El Salvador ha 
tenido un comportamiento creciente. 5

Según el Cuadro $\mathrm{N}^{\circ} 2$, la ayuda externa total en relación al PIB ( $\mathrm{AE} / \mathrm{PIB}$ ) tuvo un comportamiento heterogéneo, $2.48 \%$ en promedio en los años 70, para más que triplicar su participación promedio durante los años 80 (7.83\%). En los años 90 se mantuvo con un $6.9 \%$. A nivel promedio, durante todo el período, la ayuda externa representó un importante $6.49 \%$ en relación al PIB, lo que equivale a decir que de cada 100 dólares generados en la economía, la ayuda externa total proveía de 6.49 dólares. Vale decir que, el grueso de esa ayuda se concentró en los años 80 , posiblemente su explicación -además de la financiación, en parte, de la guerra- se encuentre en las crecientes necesidades para financiar en el año 1987 los resultados del terremoto de finales de 1986, ocurrido en el Area Metropolitana de San Salvador. 6

La ayuda externa dirigida al sector social desde 1973 a 19927 ascendió a 2,498.6 millones de dólares, equivalentes al $50.78 \%$ del monto total de la ayuda. En cada una de las décadas, de acuerdo a los años seleccionados, la ayuda externa social siempre es superior al $\mathbf{4 2} \%$ del total de la ayuda externa (AES/AE). Esto significa que el sector social representó la mayor prioridad por parte de los flujos externos.

En términos generales, la ayuda externa social incrementó su participación respecto al presupuesto nacional (AES/PN) de $6.4 \%$ entre $1973-79,22.85 \%$ entre $1980-89$ y $23.72 \%$ entre $1990-1992$.

El promedio de participación del gasto público destinado al desarrollo social respecto del PIB (GPDS/PIB) bajó, en todo el período, siendo su participación promedio apenas de $4.39 \%$. Mientras que la ayuda externa social respecto del PIB (AES/PIB) creció, llegando a una participación promedio en todo el período de 3.3\%. Asimismo, la participación de la ayuda externa social respecto del gasto público (AES/PN) muestra un ascenso claro, pasa de $6.4 \%$ en el período $1973-79$, a $22.85 \%$ en la década siguiente, para representar el $\mathbf{2 3 . 7 2 \%}$ en los primeros tres años de los 90 . Esto significa que en el período 1973-92 en promedio por cada 100 dólares de gasto público, la ayuda externa social aportó 19.5 dólares; también significa que la ayuda externa compensó la caída de los fondos nacionales y pudo impedir un deterioro mayor de las condiciones 
de vida de la población.

Parece ser que la ayuda externa ha impedido el deterioro mayor en las condiciones de vida de la población en cuanto que, del total de gastos sociales, la ayuda externa (AES/GPDS) aportó en promedio 75.07 dólares por cada 100 que se destinaron con recursos internos. El ascenso de la ayuda externa en el área social respecto del gasto social interno, pasa de representar $16.6 \%$ entre 1973-79, $78.53 \%$ entre $1980-1989$ y un asombroso $94.55 \%$ entre 1990-1992. Por lo tanto, la dependencia de fondos externos para el funcionamiento del sector social es bastante evidente.

Sobre la base del total de flujos recibidos por El Salvador en concepto de ayuda externa en el área social, cabría esperar un impacto importante en términos de la ampliación de la estructura productiva, lo mismo que un mejoramiento en las condiciones de vida de la mayoría de su población. Sin embargo, los rezagos en la política social y las carencias sociales que padecen los salvadoreños, hacen suponer resultados poco alentadores.

Según los datos y tendencias hasta aquí desarrollados, adelantamos las siguiente conclusiones:

a) El sector social ha sido el mayor receptor, y por tanto el más beneficiado de la ayuda externa en el período 1973-1992. Ello refleja la prioridad de la ayuda externa en materia social.

b) El sector social en términos de orientación del gasto proveniente de fuentes nacionales, ha tendido a menguar durante todo el período de análisis. Tal situación refleja la pérdida de prioridad de este sector en términos de la política nacional, con lo cual se contradicen las declaraciones de políticas nacionales en favor de los pobres de El Salvador.

c) El sector social, ha recibido cuantiosos flujos de ayuda externa, lo que permitiría inferir, o al menos cabría esperar, una mejora sustancial en los indicadores de desarrollo social. En consecuencia, no solo caría suponer que la magnitud de la pobreza habría descendido sino que la calidad de vida de los salvadoreñs habría mejorado ostenciblemente. 


\section{Ayuda externa social por subsector social}

os flujos de ayuda externa dirigida al sector social se clasifican Len 2 grandes rubros, los programas sociales propiamente, que abarcan el $67.9 \%$ del total de la ayuda externa social y los programas públicos no sociales ${ }^{8}$ que representan el $32.1 \%$ del total entre 1973 y 1992 (Cuadro $\mathrm{N}^{\circ} 4$ ). A nivel global, los programas sociales que participaron del mayor flujo son los de "ayuda alimentaria" con $19.8 \%$ seguida de los programas de saneamiento y medio ambiente que concentraron el $11.3 \%$, seguido del sub-sector salud $10.5 \%$, desastres y emergencias $9.5 \%$, educación $7.4 \%$, los programas rurales $0.8 \%$, otros programas sociales $4.4 \%$.

Los programas de ayuda alimentaria absorbieron 493.6 millones de dólares y 43 proyectos. Vale recalcar que de este monto, el $80 \%$ de los flujos y el $76 \%$ del número de proyectos fueron ejecutados en la década de los 80 . Tales programas, por definición, no se traducen en mejoramientos en la actividad productiva en el corto plazo, más bien su contribución puede inferirse de manera indirecta, en la posibilidad de haber amortiguado la caída en los niveles de desnutrición de la población beneficiaria9.

La importancia de los programas de saneamiento y medio ambiente, se explican por el grave deterioro en el país en ambos subsectores. Desde la década de los setenta era evidente que dentro de la región, incluso a nivel latinoamericano, El Salvador presentaba indicadores de deterioro ecológico realmente dramáticos, se considera el país ecológicamente más devastado de América Latina. Más del $95 \%$ de sus bosques tropicales de hojas caducas han sido destruidos y más del $77 \%$ de la tierra sufre de severa erosión. De acuerdo a la FAO, el país se encuentra en un franco proceso de desertificación. Como una consecuencia de ello, casi todas las especies de animales salvajes se han extinguido o están al borde de la extinción sin que haya esperanzas realistas de revertir tal proceso. Por otra parte, en el área metropolitana de San Salvador, el $13 \%$ de la población habita sobre terrenos en riesgo de derrumbarse o demasiado próximos a fuentes de contaminación 10 . A esto se agrega un estudio sobre fuentes hidrográficas que mostró que el $90 \%$ de las aguas superficiales del país se encuentran contaminadas. 11 No obstante, esa relativa preocupación y un monto de recursos externos de más de 282.9 millones de dólares, la 
situación del subsector continúa siendo grave. En este sentido, la ayuda externa no parece haber revertido un proceso de deterioro ecológico de manera significativa en El Salvador, por lo tanto su contribución ha sido muy reducida.

El rubro de desastres y emergencias absorbió 237.2 millones de dólares, el $9.5 \%$ de la ayuda social, lo que explica este comportamiento, es la situación de guerra y el terremoto de 1986. El 93\% del total de flujos se concentran en la década de 1980, lo cual viene a corroborar la presunción que su destino ha sido de tipo asistencial y no formativa. Lo anterior refleja que, uno de cada diez dólares de ayuda externa social se utilizó para cubrir déficits de consumo temporales, que no se tradujeron en una modificación en la capacidad productiva interna.

El subsector salud acumuló un total de 262.6 millones de dólares, $10.5 \%$, en ayuda externa, ello se explica por la presencia de enormes déficits en esa cartera de estado, al deterioro acumulado durante las últimas tres décadas y a la persistencia del conflicto armado durante los años ochenta.

Los flujos dirigidos a educación, ascendieron a 185.9 millones de dólares, $7.4 \%$ de la ayuda externa social. Pese a esos montos más los flujos domésticos, educación continúa acumulando deficiencias y carencias que atañen al subsector y que se reflejan de manera negativa en aspectos económicos.

Los programas rurales apenas representan el $0.8 \%$ de la ayuda social, quizá porque este subsector tiene una cercanía natural con el sector agropecuario y no con el sector social. La inclusión en este aspecto se debe a la consideración por compensación de tierras, desarrollo rural y desarrollo rural industrial, que como se muestra no es significativo.

El $4.4 \%$ de la ayuda social se define como otros programas sociales, los cuales incluyen generación de empleo, programas de género, demografía y servicios sociales. En la década 1973-79 no se registraron flujos externos en este sentido, lo cual quiere decir que este tipo de proyectos comenzaron a desarrollarse a partir de 1980, los cuales parecen haber ganado mayor importancia en los años 90, ya que en solo tres años superaron el flujo de ayuda externa de la década pasada. Creemos que dentro de este este subsector, los 
programas que cobraron mayor importancia fueron los programas de género y servicios sociales. En este sentido se destinaron en 13 años 110 millones de dólares. Estos proyectos, amén de la generación de empleo, sólo causan efecto en el mediano o largo plazo.

El rubro de programas públicos no sociales, absorbió el $32.1 \%$ de la ayuda social, 801 millones de dólares, por la clasificación de programas que en él se incluyen, podría decirse que la ayuda se diluyó en un conjunto muy grande de proyectos de diversa índole; precisar su impacto sobre el desarrollo social, es una tarea que rebasa los límites de este estudio. Sin embargo, vale decir que tanto su monto, como su representación porcentual equivale a un tercio de la ayuda social y que pese a su ambigua clasificación tales programas tienen la cualidad de haber sido utilizados por el gobierno para la promoción específica de proyectos heterogéneos.

En términos del número de proyectos realizados en el conjunto del área social, se registra un comportamiento heterogéneo. El número de proyectos debe analizarse con cierta reserva puesto que muestra nada más las cifras, pero no cualifica la importancia de los mismos. Por ello invitamos al lector a hacer sus propias conclusiones.

A partir de la información antes descrita, hacemos las siguientes inferencias:

a) Los subsectores más favorecidos de la ayuda externa durante todo el período fueron: ayuda alimentaria, saneamiento y medio ambiente, salud, desastres y emergencias y educación. Los programas menos favorecidos por los flujos externos fueron: los programas rurales, vivienda y desarrollo urbano y otros programas sociales.

b) Tres de cada diez dólares se diluyeron en un extenso conjunto de programas dirigidos al sector público, pero no son considerados estrictamente de carácter social.

c) La ayuda externa por subsector ha tenido un comportamiento ascendente, que parece compensar el decrecimiento respecto al gasto público en desarrollo social interno.

d) A medida que aumenta el número de proyectos su valor promedio percápita desciende y viceversa. 
e) Los proyectos cuyo valor promedio es menor, se ejecutaron en los subsectores de desastres y emergencias, salud, educación, otros programas sociales. Los proyectos cuyo valor promedio más que triplica a los subsectores anteriores son los proyectos de vivienda y desarrollo urbano, ayuda alimentaria y saneamiento y medio ambiente.

f) El mayor número de proyectos se realizaron en el período $1980-89$, concentró el $75 \%$ de los fondos y el $70 \%$ de los proyectos. En el período 1990-92 la tendencia a la realización de proyectos parece ser la misma que la década anterior. Es decir, que a partir de los primeros tres años de la presente década no se observa una disminución ni en el número de proyectos ni en los flujos de ayuda externa.

\subsection{Ayuda externa social por subsector y gasto público}

7 ratando de inferir cuál es la importancia de la ayuda externa

1 social en los diferentes subsectores sociales respecto del presupuesto nacional y del gasto público en desarrollo social, se observan las siguientes tendencias. (Cuadro $\mathrm{N}^{\circ}$ )

La importancia de la ayuda externa por subsector social en relación al presupuesto nacional es ascendente en los diversos períodos.

Dentro de los programas sociales, el subsector con mayor peso en todo el período fue el de ayuda alimentaria, seguido de saneamiento y medio ambiente (11.32\%) y edudación (19.76\%). El resto de subsectores representaron menos del $10 \%$ del total de ayuda social.

En relación al presupuesto nacional, la ayuda externa por subsector respresentó el $19.5 \%$ y el $75 \%$ del gasto público en desarrollo social. Con ello lo que se evidencia es la relevancia que la ayuda externa cobró para atender al sector social.

El sector social ha sido beneficiado por cuantiosos montos de ayuda externa que permitieron la financiación de diversos proyectos, ello implicó una pérdida de importancia en la financiación a partir de flujos internos.

El peso importante de la ayuda externa dirigida al sector social, 
lo coloca en una situación crítica dado que si se considera la disminución de los flujos externos a futuro, el sector más desprotegido, y por tanto más impactado, sería precisamente el más dependiente de la ayuda externa, es decir el sector social.

\subsection{Ayuda externa social por tipo y subsector}

La evolución de la ayuda externa dirigida al sector social atendiendo el tipo de ayuda y el sub-sector tiene un comportamiento heterogéneo (Cuadro $\mathrm{N}^{\circ} 6$ ). El $66.34 \%$ de la ayuda al sector social se orientó para ampliar la formación de capital fijo; $4.3 \%$ a la no formación de capital fijo; $0.11 \%$ a cooperación técnica y $29.25 \%$ como ayuda no clasificable por sector (ayuda alimentaria y desastres y emergencias). Tal comportamiento debió garantizar una mejora sustancial en los indicadores de desarrollo social, puesto que el grueso de la ayuda externa se utilizó para ampliar la capacidad productiva del sector social.

La ayuda extema por tipo, deja evidencia respecto de las prioridades de los países donantes. Es bastante claro que se tiende a apoyar programas dirigidos a ampliar la capacidad productiva, es decir a la formación bruta de capital, mientras que porcentajes muy exiguos se destinaron a cooperación técnica y un tercio de la ayuda se tipifica como ayuda asistencial, puesto que va dirigida a desastres y emergencias y ayuda alimentaria.

El subsector que dentro del tipo de formación bruta de capital (FBC) concentró el mayor flujo de fondos, se refiere a los programas públicos no sociales, con un $43.16 \%$. Dentro de los programas sociales destacan los programas del medio ambiente con $17.07 \%$, salud con $15.47 \%$ y educación con $10.16 \%$. El mismo comportamiento se presenta si se analiza por el lado de los proyectos ejecutados.

En cuanto a la ayuda externa que no es formación bruta de capital (NFBC) se destaca evidentemente el subsector de programas públicos no sociales con el $78.6 \%$ de la ayuda, y los programas sociales con el $21.39 \%$, donde educación absorbió el $15.69 \%$. La misma tendencia se observa por el lado del número de proyectos ejecutados. 
La ayuda externa destinada a la cooperación técnica $(\mathrm{CT})$, se concentró en programas públicos no sociales con un $44.55 \%$ y los programas sociales con $55.45 \%$. Dentro de estos últimos repuntaron otros programas sociales con $16.33 \%$ de la ayuda. Con este tipo de ayuda únicamente se desarrollaron 15 proyectos con una tendencia similar a la de los porcentajes descritos.

El tipo de ayuda no asignable por sector (NAS) si representa un porcentaje que equivale casi a la tercera parte de los fondos destinados al área social. Por la clasificación de los programas en él contenidos (ayuda alimentaria y desastres y emergencias) se puede decir que este tipo de ayuda tuvo un carácter asistencial.

\subsection{Ayuda externa social por donante y subsector}

$\mathrm{F}^{\mathrm{l}}$ Cuadro $\mathrm{N}^{\circ} 7$ muestra los flujos de ayuda social que El SalvaCdor recibió en el período objeto de análisis por donante y subsector. En términos generales la ayuda bilateral absorbió el $71.1 \%$ de total (1,776.6 millones de dólares) y la ayuda multilateral fue del $28.9 \%$ (722 millones de dólares).

Del total de flujos provenientes de fuentes bilaterales destaca la participación de Estados Unidos, quien ha proveído el $89.85 \%$ de los flujos (1,596 millones de dólares). Esta situación permitiría inferir que los Estados Unidos tuvo mayores posibilidades de influenciar las medidas de política social implementadas en el país, dado el tipo de condicionalidad que la ayuda representa.

Desagregando la ayuda proveniente de los Estados Unidos por subsector, podríamos afirmar que la orientación por subsector fue bastante asistencial en cuanto que sólo la ayuda alimentaria y desastres y emergencias participaron de más del $40 \%$ de los fondos. Los diversos programas de apoyo al sector público no sociales absorbieron el $34.49 \%$, salud el $10.82 \%$, educación el $6.85 \%$, para dejar pequeños márgenes al resto de subsectores.

La ayuda proveniente de fuentes multilaterales equivalió a cerca de la tercera parte del total de los flujos; podría también decirse que la posibilidad de influenciar la adopción u orientación de cierto tipo de medidas sociales, también es importante para los cooperantes multilaterales. 
La ayuda multilateral se concentró mayoritariamente en el rubro ayuda alimentaria y medio ambiente, seguido de programas públicos no sociales. Los subsectores cuya participación en la ayuda multilateral fue poco significativa fueron salud, educación y vivienda.

Entre los Estados Unidos y las agencias multilaterales se destinó más del $90 \%$ de los fondos, lo cual quiere decir que estos donantes tuvieron la mayor capacidad de definir el tipo de orientación que se requería para la ayuda.

El tercer proveedor de ayuda externa ha sido Europa Central y Occidental, quienes han participado del $5.98 \%$ del total de flujos de carácter bilateral. En este caso no prevalecen tendencias obvias en los subsectores, más bien la ayuda parece estar diluida. Los países Nórdicos y Canadá participaron con el $3.23 \%$ y prevalece la ayuda asistencial dirigida a programas de desastres y emergencias. Japón, por su lado, únicamente participó del $0.93 \%$ y no presenta tendencias marcadas en los subsectores.

\title{
3.4 Ayuda externa social por donante y tipo
}

\begin{abstract}
$\Delta$ nalizando la ayuda social por donante y tipo (Cuadro $N^{\circ} 8$ ), A ya se dijo que casi el $90 \%$ de la ayuda bilateral provino de Estados Unidos; la mayor orientación por tipo se concentró en el apoyo de proyectos dirigidos a incrementar o fortalecer la formación bruta de capital (52.93\%), esto significa que más de 800 millones de dólares debieron contribuir a la ampliación de la capacidad productiva en los sectores sociales, sin despreciar un $41 \%$ de la ayuda dirigida a atender los desastres y emergencias y ayuda ealimentaria. Vale decir que, los Estados Unidos no registraron flujos en concepto de cooperación técnica.
\end{abstract}

La ayuda del resto de fuentes bilaterales privilegió la ayuda no asignable por sector y la formación bruta de capital, dejando pequeños residuos a la no formación bruta de capital y cooperación técnica.

Llama la atención que de fuentes multilaterales casi el total de la ayuda estuvo dirigida a la formación bruta de capital, resaltando el hecho de que en la década de los 90 parecen tener gran interés en este tipo de orientación puesto que su monto total en 3 
años equivalió a casi al total de la década anterior.

Con la información presentada en este apartado se sintetizan las siguientes conclusiones:

a) Los programas sociales en su conjunto absorbieron $1,776.6 \mathrm{mi}-$ llones de dólares, el mayor flujo de toda la ayuda externa recibida en el país, para dejar a programas públicos no sociales 722 millones de dólares.

b) En orden de importancia, el tipo de ayuda que prevalece estuvo orientada a la formación bruta de capital (63.34\%), seguida de ayuda para desastres y emergencias y ayuda alimentaria $(29.25 \%)$, luego ayuda para no formación bruta de capital $(4.3 \%)$ y asistencia técnica $(0.11 \%)$.

c) Los subsectores más favorecidos por la formación bruta de capital fueron los programa públicos no sociales, seguidos de saneamiento y medio ambiente, salud, educación y otros programas sociales.

d) La ayuda no asignable por sector representó casi la tercera parte de la ayuda social e incluye ayuda alimentaria y desastres y emergencias.

e) La cooperación técnica fue poco significativa en el total de la ayuda.

f) La ayuda orientada a la no formación bruta de capital privilegió a los programas públicos no sociales y educación.

g) Prevalece la ayuda de carácter bilateral, en donde el mayor peso lo ejercen los Estados Unidos, seguidos de Europa Occidental y Central, países Nórdicos y Japón. La ayuda multilateral equivale a la tercera parte del total de ayuda social recibida.

h) La ayuda proveniente de Estados Unidos se concentró en programas sobre ayuda alimentaria, salud y desastres y emergencias.

i) La ayuda proveniente de fuentes multilaterales se concentró también en los programas de ayuda alimentaria, saneamiento y medio ambiente y en los programas públicos no sociales.

j) Los sub-sectores del sector social menos favorecidos por la ayuda externa fueron los programas rurales, vivienda y desarrollo urbano. 
k) El grueso de la ayuda por tipo, por subsector y por donante se concentró en la década de los 80 , una década caracterizada por la inestabilidad social, política y económica. Constituye una explicación sobre los resultados poco significativos de la ayuda externa que se analizan más adelante. Vale advertir que los primeros tres años de la década de los 90 no significaron disminuciones sustantivas en los niveles de la ayuda, todo lo contrario de preveerse esa tendencia, se podrían superar los montos de la década anterior. No obstante, eso es poco probable si se analizan las nuevas tendencias de la cooperación externa tanto bilateral como multilateral.

\section{Condicionalidad}

A nivel general, es importante señalar que el $53.07 \%$ del total Ade la ayuda externa tiene un carácter de donativo, el $31.11 \%$ es una combinación de donación y préstamos (en su mayoría el donativo excede el $70 \%$ ), el $12.69 \%$ se clasifica como ayuda oficial para el desarrollo y el restante $3.12 \%$ representa ayuda proveniente de los gobiernos donantes. Se puede asegurar que al menos el $75 \%$ de la ayuda externa tiene un carácter no retornable, lo cual significa que el país no destinará fondos para su pago. Las condiciones de uso de los donativos, dependieron de los convenios particulares firmados para su efecto y el tipo de condicionalidad puede ser diverso dependiendo del donante y del tipo de ayuda. (Cuadro $\mathrm{N}^{\circ}$ 9)

De acuerdo al análisis hecho en páginas anteriores puede decirse que la ayuda externa con mayor posibilidad de establecer condicionalidades, ya sea porque es donada como por el monto de los flujos, ha sido la proveniente de Estados Unidos y la de agencias multilaterales. De ahí que se infiera que por esta razón estas dos fuentes tuvieron la capacidad de influir en la determinación de la política social.

\section{Las instituciones de "lo social"}

T a evidencia muestra que el desorden, la falta de transparencia, Lla ineficiencia e ineficacia, son características que se encuentran en las estructuras institucionales de gobierno. Tal situación parece remarcarse en las instituciones dedicadas a labores sociales. 
Existen fundadas sospechas de que cualquier aumento en los márgenes presupuestarios en este tipo de instituciones, o se quedará a mitad del camino o no tendrá los frutos esperados. El caos en las instancias gubernamentales ha sido tal, que es hasta el año 1993, que en El Salvador se han efectuado estudios a nivel de diagnóstico para determinar, inclusive, el número de empleados contratados en los ministerios de educación, salud y en la institución de previsión social.12

Un fenómeno que ha sido claro y que lo ha generado el financiamiento externo, especialmente cuando se refiere a préstamos, es la creación dentro de las instituciones de gobierno de instancias de administración paralela, encargadas de agilizar el destino de la ayuda externa. Este fenómeno se ha dado como resultado de la burocracia estatal, de experiencias en donde se ha visto obstaculizado el otorgamiento de la ayuda a sus beneficiarios directos.

También debe advertirse que tal fenómeno ha sido posible por la escasa capacidad de planeación, operación y particularmente de evaluación de los proyectos en el ámbito nacional. En efecto, uno de los problemas obvios en este sentido, ha sido la falta de información; desde 1971 no se contaba con censo nacional, y a juzgar por los resultados del efectuado en 1992 parecen haber serios problemas de confiabilidad. La información proveniente de la Encuesta de Hogares de Propósitos Múltiples, que se elaboró desde 1985 hasta principios de 1992 consideró únicamente el sector urbano. Esta deficiencia refuerza los obstáculos para elaborar diagnósticos suficientemente confiables a partir de los cuales se pudiesen derivar relaciones de causalidad.

De igual modo, son evidentes los problemas existentes en relación a las metodologías y técnicas de elaboración de proyectos en el área social, sobre todo porque el área en si, además de ser amplia, presenta complejidades que otros sectores no tienen. Ha sido en este sentido, notoria la participación de las agencias internacionales mediante la asignación de recursos externos para la formulación adecuada de los proyectos. Si bien se cumple con las presiones de tiempo, el país no asimila la experiencia.

El sector gubernamental ha tendido a contratar personal relativamente bien remunerado con baja capacitación y el personal 
gerencial tiene una remuneración que equivale a la mitad de lo que ganaría en el sector privado, esto desestimula la contratación de personal con alta capacitación. Así mismo se constituye en una presión para que los puestos gerenciales sean ocupados por personal desmotivado o poco calificado. Las estructuras de administración paralela, creadas para subsanar esas dificultades, si bien resuelven el problema de administración y de eficiencia en el otorgamiento de la ayuda a sus beneficiarios directos, contribuyen a ampliar las desigualdades salariales, de estatus e incluso a burocratizar aún más los procesos de toma de decisiones.

Existe un problema bastante grave en las estructuras de gobierno, esta se refiere a la escasa capacidad de inversión del sector público, ya que durante toda la década pasada y los años que corren en la presente, el $85 \%$ en promedio de los presupuestos ministeriales se dedicaron a funcionamiento, descartándose casi en todos las posibilidades de inversión. Cuestión que se traduce en un escaso o nulo incremento en la capacidad productiva del Estado. A este respecto ha sido frecuente el argumento de que la poca capacidad de inversión por la vía del presupuesto nacional se compensa con fondos del presupuesto extraordinario, sin embargo la información disponible al efecto es tan escasa como la existente en relación a la ayuda extema. De ahí que lo único que queda es hacer presunciones o generalizaciones.

Una cuestión que se observa con bastante claridad es el hecho de que, el Estado y el Gobiemo como expresión del Estado, ha sido objeto de severas críticas de efectividad y eficiencia en materia económica, de ahí la justificación de constreñirle sus competencias productivas en el marco de los programas de ajuste estructural. No es ningún secreto, ni en El Salvador ni en ningún país latinoamericano las reconocidas insuficiencias del sector público para la prestación de los servicios de su competencia. Partiendo de ese hecho, resulta contradictorio que a esas "instituciones de lo social" se les adjudique hoy día la mayor de la tareas: la disminución de la pobreza.

Esta disgresión se hace con el afán de advertir de que si el Estado no fue capaz de manejar adecuadamente la gestión economica, son escasas las argumentaciones que le acrediten como el 
mejor para resolver los mayores males sociales de los salvadoreños.

La ayuda externa no parece haber impactado en sentido positivo y de manera significativa la institucionalidad de lo social, ni con semejante apoyo el Estado fue capaz de resolver los problemas de marginación social y pobreza ¿qué indica que ahora pueda hacerlo?

La ayuda externa para El Salvador disminuirá, y si esta privilegió el área social, no cabe duda que será justamente ese sector el mayor afectado. El país que recién sale de un período de guerra y que tiene graves problemas financieros para el cumplimiento de los acuerdos de paz, además de ir gradualmente asumiendo esa "deuda social", deberá asumir con mayor vigor la tarea de financiar el área social con recursos internos y ya no con fondos provenientes del exterior.

Sin embargo esa posibilidad puede verse seriamente afectada si se consideran las siguientes restricciones: la carga tributaria para 1993 fue de $9.5 \%$ en relación al PIB, la regresividad de la misma, luego de una reforma fiscal en 1992 y un ajuste en 1995. Se especula un porcentaje de evasión que podría sobrepasar el $50 \%$ de la recaudación total. La tendencia previsible a la disminución de la ayuda externa, las rigideces institutucionales para la asignación del gasto y la coordinación interinstitucional, la deuda pública, el déficit fiscal, las exigencias para financiar los acuerdos de paz, etc.

Por su lado, la ayuda externa ha contribuido a la creación de dos instituciones que han tenido cierto impacto en materia social en los años noventa. La primera fue el Fondo de Inversión Social (FIS) encargado de ejecutar los programas de compensación social y de atender las necesidades más apremiantes de la población que vive en condiciones de pobreza y extrema pobreza.13 La otra institución fue la Secretaría de Reconstrucción Nacional (SRN), la cual fue recompuesta al tenor del Programa de Recontrucción Nacional (resultado de la firma de los acuerdos de paz).14.

En términos de orientación del gasto, los programas de las dos instituciones a nivel nacional en 1993, representó el 1.07\% del PIB.15

A nivel de desarrollo institucional se puede destacar la autono- 
mía ganada por el FIS y la SRN, la efectividad en el desarrollo de sus proyectos. Aunque en ambos casos se han señalado vacíos tales como: la dependencia de fuentes externas de financiamiento, la focalización como criterio de asignación de rescursos en un país cuyo porcentaje de pobreza azota a cerca de dos tercios de su población, el carácter compensatorio y por tanto coyuntural de sus programas. En el caso de la SRN hay un señalamiento adicional que consiste en la presunción del carácter político que parece aplicarse en la asignación de recursos 16 .

Por otro lado, el programa de Educación con Participación de la Comunidad (EDUCO) en el sector educativo, es una experiencia que merece revisión ya que presenta la cualidad de generar participación de la población beneficiaria en la supervisión de los proyectos y constituye un mecanismo de ampliación de cobertura a nivel de educación básica. No obstante, también existen dudas sobre su efectividad en ese sentido, además de que dicho programa se ha financiado exclusivamente con fondos externos 17.

Una experiencia análoga en el sector salud la representn los Sistemas Locales de Salud (SILOS). El principal potencial de esta experiencia radica en la posiblidad de desarrollar una administración oportuna, eficiente y transparente mediante la generación de un mecanismo de coordinación interinstitucional18, que se traduzca en un excelente servicio de salud para la comunidad.

Las experiencias del sector educación y salud, han sido posible debido a la participación de la cooperación externa. Podría decirse que recién se inicia un proceso de capitalización de programas con potencial que involucran la asistencia externa.

\section{Ayuda externa y pobreza en El Salvador}

$\Lambda$ efecto de hacer un análisis sobre el impacto de la ayuda Aexterna sobre la evolución de las condiciones de vida de la población, debe advertirse que no existe línea directa de causalidad entre ayuda externa y pobreza. Por lo menos la información aquí presentada no permite hacer esas conexiones de manera directa aunque sí se pueden derivar algunas tendencias.

En este apartado se analizará la evolución de algunas condiciones de vida de la población: la evolución de la pobreza, a partir de 
la metodología de línea de pobreza, educación, salud, pobreza y acceso a servicios básicos.

\subsection{Situación de pobreza en El Salvador}

$\square^{n}$ relación a la variable pobreza, es necesario aclarar que por ¿ ser un concepto normativo no existe un sólo método para medirla. La pobreza cambia de lugar en lugar y de época en época, la magnitud de las necesidades básicas también cambia en función del tiempo y el espacio, y de otras variables tales como: el desarrollo económico, las costumbres o los precios, por ello es difícil establecer comparaciones. Los diversos métodos para medir la pobreza (Necesidades Básicas Insatisfechas, Método Integrado de Medición de la Pobreza, Línea de Pobreza, deuda social de PREALC, etc.) se prestan a ejercer con ellos o mejor dicho con sus resultados, ciertas presiones y a manipular los datos.

Dejando de lado las dificultades metodológicas, según los datos existentes, el cuadro $\mathrm{N}^{\circ} 10$ resume la condición de pobreza a nivel nacional, por áreas geográficas en $\mathbf{4}$ años seleccionados.

Para 1980, la CEPAL reporta que el 58\% de los habitantes de El Salvador se encontraban en situación de pobreza, $17.3 \%$ en pobreza relativa y más del $50 \%$ de la población en pobreza extrema. En efecto, 1 de cada dos salvadoreños no tenían ingresos suficientes para cubrir el costo de la canasta alimentaria. La situación se agudiza aún más en el área rural donde más del $75 \%$ de la población se encontraba en situación de pobreza.

El flujo de ayuda externa dirigida al sector social, hacia finales

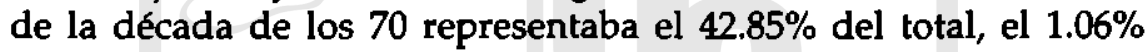
del PIB, el $6.4 \%$ de los gastos del presupuesto nacional y el $16.6 \%$ de los gastos nacionales destinados al desarrollo social. Con todo y los cuantiosos flujos de ayuda externa, el indicador social más sensitivo, la pobreza, presentaba su punto más agudo. Lo cual podría implicar dos cuestiones. La primera, que de no haber sido por la ayuda externa, los niveles de pobreza serían mayores y la segunda, que la ayuda externa no se canalizó y utilizó adecuadamente de manera que tuviese un impacto notorio sobre los niveles de pobreza. 
Para 1985 los datos disponibles, indican un empeoramiento en las condiciones de vida de los hogares salvadoreños. La tendencia se repite, la situación es peor en las áreas rurales que en las áreas urbanas.

En el período 1991-92 si bien los indicadores de pobreza proporcionados por instancias oficiales, indican un mejoramiento, puede afirmarse que los niveles de pobreza todavía son cuantiosos: $59.7 \%$ a nivel nacional, $66.1 \%$ en el campo y $53.8 \%$ en el área urbana.

Para la década de los 80 , la ayuda externa dirigida al sector social, representó en promedio el $51.35 \%$ de la ayuda externa total, el $4.02 \%$ del PIB, el $22.85 \%$ de los gastos del presupuesto nacional y el $78.53 \%$ de los gastos internos destinados al desarrollo social. El total de flujos de ayuda externa social ascendió a 1,789 millones de dólares. El monto de ayuda externa más los fondos internos destinados al área social, permitirían suponer un mejoramiento más notorio en los indicadores de pobreza.

La reducción porcentual de la pobreza, tal como aparecen en el período 1991-92 no sugiere de ninguna manera que el problema se ha resuelto, todo lo contrario. Si con grandes cantidades de ayuda externa no se logró un mejoramiento más importante en los indicadores de vida de los hogares salvadoreños, cabe suponer al menos 2 situaciones: que el monto de recursos externos e internos fueron insuficientes para abordar el problema, y que la ayuda no se utilizó en lo proyectado; por lo tanto, los fondos no llegaron de la manera supuesta a los beneficiarios.

En los 90, con altas tasas de inflación acumulada y con el impulso de medidas de estabilización y ajuste estructural -cuyos primeros impactos contraen la demanda- es poco probable suponer que la pobreza tienda a disminuir. Es posible que porcentualmente los indicadores mejoren, pero el cuadro antes señalado muestra que en términos absolutos las cifras aumentan significativamente.

Del análisis anterior cabe hacer algunas consideraciones:

a) El grueso de los hogares salvadoreños, no tiene capacidad de garantizar la satisfacción de sus necesidades básicas. 
b) La situación de pobreza es más aguda en el campo que en la ciudad, aunque pudiera observarse una chara tendencia a su profundización en las ciudades.

c) No existe relación directa de causalidad entre ayuda externa social y pobreza. Puede aventurarse la presunción que la ayuda externa amortiguó la caída de los indicadores sociales, o dicho de otra manera, contribuyó a disminuir la pobreza porcentualmente, pero debe aclararse que también los recursos externos provenientes de los remesantes son cuantiosos y que a partir de ellos pueden hacerse las mismas inferencias. 19

d) No cabe duda que los cuantiosos recursos provenientes de ayuda externa, no afectaron de manera decisiva los indicadores de pobreza.

\subsection{Pobreza y evolución de indicadores sociales}

$\Psi \mathrm{n}$ los 20 años de análisis, objeto de estudio, puede afirmarse ¿que los problemas básicos que sufre el subsector de educación en El Salvador no son nuevos y siguen siendo los mismos en 1970 como en 1992: baja escolaridad en la población en edad escolar, altas tasas de analfabetismo y baja cobertura del sistema educativo. En El Salvador, una de cada tres adultas no sabe leer, $29 \%$ de las personas con 16 años y más no sabían leer en 1992. La tasa de analfabetismo era de $24 \%$ para los hombres y de $32 \%$ para las mujeres. En América Latina sólo Guatemala y Honduras tenían en 1990 una proporción semejante de analfabetos y Haití una tasa superior.

En 1979 , el $54 \%$ de la población había aprobado tercer grado o menos de primaria, 13 años más tarde, $42 \%$ de la población se encontraba en la misma condición. En el mismo período, el porcentaje de personas con 10 a 12 años de escolaridad, sólo aumentó de $9 \%$ al $13 \%$, y con 13 años y más $3 \%$ a $7 \%$. Es decir, en 1992 , como en 1979, la población entre 15 y 59 años de edad es predominantemente una población con muy bajos niveles de escolaridad.

En 1992 sólo el $76 \%$ de los niños con edades comprendidas 
entre 7 y 12 años están matriculados entre primero y sexto grado de educación básicas. Sólo $70 \%$ de aquellos con edades entre 7 y 15 años están matriculados entre primero y noveno grado. Sólo $18 \%$ de los alumnos con edades entre 16 y 18 años están matriculados en bachillerato.

Dada la estructura actual del sistema educativo para cada nueva generación de salvadoreños, menos de una de cada dos personas podrá alcanzar el sexto grado, sólo una de cada tres culminará la educación básica y sólo una de cada cinco culminará el bachillerato. A este ritmo el progreso en aumentar los niveles educativos de la población será muy lento.

Al problema de la insuficiencia de los resultados del sistema educativo se agrega el de la baja calidad de la educación que los estudiantes reciben y son perceptibles las pocas vinculaciones entre educación y sistema productivo. 20

Otro problema fundamental es la repitencia y la deserción, sólo $47 \%$ de los alumnos que ingresan a la escuela primaria completan el sexto grado y sólo 33\% completan el noveno grado. En promedio son necesarios 10 años para producir un graduado de sexto grado y 18 para producir un graduado de educación básica. En educación media sólo el $72 \%$ de quienes inician bachillerato lo culminan y son necesarios 3.7 años para producir un graduado. En la universidad se gradúa menos de la tercera parte de los nuevos ingresos.

El sistema educativo salvadoreño progresa a un ritmo lento para tener impactos significativos en la estructura educativa de la población del país. Esto a su vez se relaciona con y se agudiza por la baja calidad de la educación que reciben los alumnos que logran avanzar en el sistema educativo. Este fracasa en todos los niveles en términos de la meta básica de lograr que los alumnos adquieran destrezas mínimas en el lapso previsto en cada ciclo. Muchos alumnos repiten $y$, eventualmente abandonan el sistema, lo cual se traduce en pérdidas del potencial humano que nunca alcanza niveles superiores de capacitación, y en costos exagerados por graduado por las bajas tasas de graduación en el tiempo previsto.21

En términos de la ayuda extema se destinaron 185.9 millones de dólares, 51 proyectos y $7.44 \%$ del total de la ayuda externa, los 
cuales fueron insuficientes para revertir los resultados anteriores. Con flujos como estos más los recursos internos sólo se explican los problemas actuales en educación, si la profundidad de los mismos el tal que ameritan un cambio radical en la manera de abordarlos.

La salud de un país siempre es la resultante del comportamiento de otros indicadores que configuran la condición socioeconómica del individuo; por ejemplo, el nivel de empleo, el tipo de vivienda, el acceso a servicios básicos, los niveles educativos, etc.

En el subsector de salud en 1980, la tasa de mortalidad infantil era de 60 por mil nacidos vivos, trece años más tarde se determinó que asciende a 56 por mil nacidos vivos; la mortalidad en niños menores de 5 años bajó entre 1980 y 1990 de 122 a 84 por mil nacidos vivos. Las enfermedades agudas todavía constituyen la principal causa de muerte y de consulta en el último quinquenio; las enfermedades diarréicas han sido la segunda causa de muerte en los menores de un año, causadas en su mayor parte por las malas condiciones de vida de la población y agravadas por el pasado conflicto armado, particularmente en áreas rurales.

Uno de los mayores males en este subsector lo constituyen las deficiencias de nutrientes que afecta en su mayor parte a los niños, mujeres y familias pobres. Según el Censo de Talla en escolares realizado en 1988, el $50 \%$ de los menores de 5 años, adolecían de algún grado de desnutrición moderada o severa. La avitaminosis A es otro de los problemas de salud pública, de donde un estudio determinó que un $36 \%$ de los niños menores de 5 años tenían niveles séricos de Retinol, superior a la cifra determinada en la década de los sesenta. La prevalencia de bocio endémico entre los escolares también sigue siendo alta $(24.8 \%)$, cifra que es mayor en otras, sobrepasando el $30 \%$. Existe además evidencia de un aumento de cretinismo congénito que pudiera estar relacionado también con deficiencias de yodo en la sal. La anemia, es una enfermedad que padecen frecuentemente las mujeres embarazadas 0 lactantes y niños. 22

Son evidentes en este subsector otro tipo de problemas como el crecimiento poblacional, la reducción dramática de mantos acuíferos, la falta de abastecimiento de agua potable, la contami- 
nación del $90 \%$ de aguas superficiales, la falta de una adecuada disposición de excretas. Todo ello continúa demandando la creatividad, esfuerzos y la necesidad de mayores recursos en este sentido por parte de salud pública.

En la década pasada se cerraron muchos centros de salud, emigró del país personal médico y paramédico, el terremoto de 1986 destruyó edificaciones de servicios médicos, las tácticas de la estrategia contrainsurgente aislaron a grandes contingentes poblacionales de los servicios médicos y del acceso a medicamentos, el cuadro epidemiológico se agravó notoriamente, la inversión en este rubro disminuyó a lo largo de la década, conforme el presupuesto aumentó en el rubro de defensa, fue disminuyendo el gasto en salud y educación. Todo ello configuró un deterioro generalizado de las condiciones de salud; condición muy difícil de superar en los próximos años.

En términos de la ayuda externa se destinaron a salud 262.6 millones de dólares, 75 proyectos y $10.51 \%$ del total de la ayuda externa. Todo ello fue insuficiente para revertir los resultados anteriores. Con flujos como estos más los recursos internos sólo se explican los problemas actuales, si la profundidad de los mismos el tal que ameritan un cambio radical en la manera de definir la política social encargada de abordar estos problemas.

En el cuadro $\mathrm{N}^{\circ} 11$ se presenta la evolución de indicadores sociales seleccionados, sobre ellos se hacen las siguientes consideraciones:

La población total crece a un ritmo acelerado, de seguir esa tendencia la población salvadoreña se habría duplicado en 30 años. También se observa la tendencia a la "urbanización", según los datos, la población rural tendió a disminuir y la población urbana creció. El fenómeno está asociado básicamente a dos variables, la industrialización y la guerra. La tendencia difícilmente sea reversible, es decir que por la razón que sea, en El Salvador deberá tenerse en cuenta la tendencia a la predominancia de la población urbana, lo cual exige de una planificación mayor que considere las nuevas demandas en el espacio urbano, sin descuidar la problemática rural.

La esperanza de vida de los salvadoreños para 1970 era de 59.1 
años, mejorándose ligeramente a 62.2 años en 1980, estimándose en 64.4 años en 1992.

Respecto al indicador de mortalidad, ciertamente en 22 años se descendió de 66.6 a 56 por cada 1000 nacidos vivos, pese a ello El Salvador se ubica dentro de los países subdesarrollados con una alta mortalidad por enfermedades prevenibles. Las causas de muerte son ocasionadas por condiciones socioeconómicas precarias. Uno de los pocos índices en los que el país muestra resultados relativamente satisfactorios es en los indices de vacunación alcanzados.

En relación al problema de la vivienda en El Salvador, vale decir que este se reduce a la falta de un techo, sino que tiene que ver con el entorno, con el hábitat. Sin embargo, es innegable que el problema de la vivienda parte de la ausencia de ella para un contingente poblacional importante. Si bien no se reduce a eso, tener claro que comienza ahí es básico para entender su dimensión.

El déficit habitacional es sustancial: 531,572 viviendas en 1978 y 10 años más tarde 450,000; tal déficit lo sufre con gran agudeza la población rural, 362735 viviendas en 1978 y 317,000 en 198823. En general el déficit habitacional es superior al $60 \%$, lo que significa que una de cada tres familias salvadoreñas no cuentan con una vivienda.

El problema cobra otras dimensiones cuando se entiende que aún cuando las familias cuentan con un techo, la vivienda presenta carencias importantes difíciles de soslayar. Por ejemplo, para 1978 el $68.2 \%$ de los hogares tenían una relación de 5 y más personas por habitación, el $82.7 \%$ ubicados en el campo y el $46 \%$ en las zonas urbanas.24 Ello significa que más de la tercera parte de los hogares se encontraban hacinados, con lo cual se agravan las condiciones de higiene de los hogares.

El grueso de las viviendas de 1978 como de 1985 tenían una sola habitación, $72.3 \%$ y $50.5 \%$ respectivamente 25 . Si bien es cierto que de un período a otro la cuestión tiene una mejoría, no se puede dejar de lado que siguen habiendo importantes desigualdades y en definitiva falta de condiciones que aseguren una vida digna a la mayoría de los salvadoreños.

Las carencias en términos de los servicios básicos reflejan tam- 
bién la falta de condiciones de habitabilidad adecuadas. En 1985, el $55.8 \%$ de los hogares salvadoreños no contaban con agua potable, el $34.5 \%$ no contaba con energía eléctrica, el $47.3 \%$ no temía servicio sanitario y 1 de cada 5 hogares vivían en viviendas inadecuadas (mesones, tugurios o colonias ilegales) 26.

No cabe duda que la población resuelve su problema de carencia de agua, comprándola a precios más elevados, recoge de los ríos o la lluvia, pero en cualquiera de las alternativas es obvio que no pueden preservarse las condiciones higiénicas mínimas.

En general, el problema de la vivienda en El Salvador es agudo, reviste grandes complejidades y azota a un sector mayoritario de la sociedad. Dicho problema si bien se ha agravado con la crisis económica y social de la década pasada, es el resultado de problemas que tienen que ver con la estructura económica y social, por lo tanto la forma de enfrentarlo no sólo debe considerar alternativas novedosas y creativas sino deberá tener presente las múltiples facetas y complejidades a su interior.

En términos de una política de vivienda, sin embargo los que deben tener prioridad son aquellos pobres que no tienen acceso a la vivienda, es decir tratar de cubrir en primer lugar el déficit habitacional, enseguida mejorar la calidad de la vivienda y los servicios básicos de los hogares que habitan mesones, tugurios o ranchos. En estas formas peculiares de vivienda reviste gran importancia y complejidad la forma de tenencia de la vivienda a la que hay que buscarle solución.

Aunque el sector de vivienda y desarrollo urbano ha sido uno de los subsectores menos favorecidos por la ayuda externa, tampoco parece que los esfuerzos internos por abordarlo hayan tenido un resultado importante, más bien el análisis anterior permite inferir un deterioro evidente en esta materia para la población salvadoreña.

\section{Consideraciones finales}

Con base en los datos expuestos sobre ayuda externa pra el período 1973-1992, es posible recopilar los principales hallazgos en los siguientes términos: 
a) El sector social ha tenido una fuerte dependencia del financiamiento externo. Cabría incluso decir, que ha habido más preocupación de la cooperación externa que de los diversos gobiernos nacionales por atender verdaderamente los problemas del sector social y de cada uno de los subsectores específicos. No obstante, los grandes flujos de ayuda no parecen haber impactado notoriamente los indicadores de desarrollo social del país; más bien se descubre una regularida a pesar de la ayuda externa en El Salvador hay más pobreza.

b) La ayuda externa ha tenido una orientación de tipo asistencial, caso contrario hubiera impactado ostenciblemente la capacidad productiva del país y hubiese mejorado notoriamente los indicadores desarrollo social. Aunque dado el perído de guerra que se vivió en la década pasada, se podría presumir que la ayuda ciertamente evitó una erosión mayor de dichos indicadores.

c) Aunque no se puede derivar con exactitud, se podría presumir que un monto importante de la ayuda recibida en la década de los ochenta fue destinada a financiar de alguna manera la guerra.

d) La gravedad de los problemas que padecen los diversos sub-sectores del área social: educación, salud, medio ambiente, agua y saneamiento, merecen mayor atención, y se plantea como condición necesaria que los fondos destinados a su atención provengan de recursos internos.

e) El camino recorrido desde la perspectiva de la ayuda externa fue insuficiente para superar las profundas carencias sociales de la mayoría de la población salvadoreña, panorama más dramático en las áreas rurales. Los cuantiosos flujos recibidos en concepto de ayuda externa reflejan la insuficiencia de las políticas sociales, la gravedad del problema social, la poca efectividad de la ayuda externa y la magnitud del desafío social.

f) El deterioro de los servicios sociales es uno de los resultados más notorios de la última década, si en El Salvador ya existía un déficit bastante importante en la mayoría de indicadores sociales, hoy, parece haber incrementado su deterioro.

f) Es innegable que a nivel nacional, cabría destacar la importan- 
cia que tiene para el país el invertir en salud y educación para potenciar las posibilidades de desarrollo y crecimiento económico a mediano y largo plazo del país. Un país que invierte poco en estos rubros está vedando sus posibilidades de desarrollo, con analfabetas y desnutridos no puede construirse una sociedad con bienestar ni democrática.

g) Los montos de ayuda externa bilateral, particularmente la proveniente de Estados Unidos pudo reforzar las políticas nacionales, en los distintos períodos, al mismo tiempo que cabría esperar una sobredetermición en el quehacer social en el país. Es obvio, que esta ayuda tuvo una orientación asistencial y no formativa, que se supeditó a la situación de guerra vivida en los ochenta y a las medidas compensatorias de los noventa.

h) Ha sido evidente además, que el área social ha adolecido de enormes carencias y no parece existir dudas de la gravedad de los problemas, de la persistencia de déficits acumulados en materia social, de los incrementos en la pobreza, de la incapacidad del modelo de ajuste de resarcir automáticamente a los pobres de sus efectos contractivos. Frente a ese reconocimiento, no obstante, ni la ayuda externa ni los gobiernos parecen acertar en la orientación de sus prioridades.

\section{NOTAS}

1. Jefa del Departamento de Economía de la UCA.

Este trabajo es una versión resumida de la investigación "Ayuda Externa y Evolución de Indicadores Sociales, 1973-1992", realizada para Fedesarrollo.

2. "Diagnostico del Sistema de Desarrollo de los Recursos Humanos de El Salvador", HIID, FEPADE, UCA, 1994, Capítulo de Síntesis.

3. Diagnóstico del Sector Salud. GAES/MIPLAN, dic, 1993. El 1 por ciento incluy financiamiento por presupuesto extraordinario

4. El porcentaje del gasto público en relación al presupuesto nacional, orientado a la Defensa y Seguridad Pública en El Salvador, según datos del Miristerio de Hacienda, crecí de $12.7 \%$ en 1979 a $25.4 \%$ en 1987 . En términos absolutos pasó de «185 millones a «894; es decir, que en 9 años se cuadruplicó dicho gasto. Una tendencia poco usual que sólo tiene su explicación por la persistencia de la guerra.

5. Vale aclarar que los 4,920.7 millones de dólares que recibió el país en concepto de ayuda externa, fue destinada a la atención de diversos sectores en la economía: agricultura, energía, etc.

6. El Area Metropolitana de San Salvador (AMSS), está compuesta por 10 ciudades, la capital San Salvador y 9 ciudades satélites: Santa Tecla, Antiguo 
Cuscatlán, Ayutuxtepeque, Mejicanos, Cuscatancingo, Ciudad Delgado, Soyapango, Ilopango y San Marcos. El AMSS albergaba en 1992 al rededor del $42 \%$ de los hogares urbanos y el $21 \%$ de la población del país. Para ampliaciones véase: "La pobreza en el Area Metropolitana de San Salvador". Sánchez, S. I., POSCAE, marzo de 1992.

7. La clasificación dentro del sector y del total del sector se hizo a partir de la base de datos de la Organisation for Economic Cooperation and Development, OECD. Los cálculos del área social se hicieron según las siguientes agrupaciones:

Educación: contempla proyectos destinados a educación primaria, secundaria y superior, entrenamiento vocacional, educación no formal, niveles de educación no especificados e infraestructura físicas.

Salud: incluye proyectos destinados a servicios de salud, planificación familiar, equipos y suministros, nutrición, entrenamiento médico, investigación médica y servicios sociales en salud

Saneamiento y Medio Ambiente: incluye salud medio ambiental que corresponde básicamente a agua potable, acueducto y alcantarillado. Incluye además, actividades destinadas al control de la contaminación ambiental.

Programas rurales: incluye compensación de la propiedad de la tierra, desarrollo rural y desarrollo rural industrial.

Vivienda y Desarrollo Urbano: incluye programas de vivienda urbana y rural y desarrollo urbano.

Otros programas sociales: incluye empleo, demografía, desarrollo comunitario, desarrollo de la mujer y servicios sociales.

Programa públicos no sociales: incluye servicios sociales y comunitarios no incluidos anteriormente, tales como: administración pública, servicios generales del gobiemo, servicios económicos, financiamiento de stocks, desarrollo industrial, servicios médicos veterinarios, servios de ganadería, sectores no especificados, ayuda multisectorial, sectores no identificables por préstamos al sector privado, acuerdos para ser asignados, financiamiento de stocks agrícolas, servicios de agua para la agricultura, desarrollo de suelos, lagos, planeación gubernamental, geofísica y geología, metereologla, desarrollo de ríos y desarrollo regional.

Ayuda alimentaria.

Desastres y emergencias: incluye ayuda para desastres y emergencias, ayuda humanitaria, ayuda para emergencias médicas, ayuda para la educación de refugiados, ayuda para emergencias alimentarias y ayuda para la reconstrucción.

8. Véase cita $N^{0} 5$ de este trabajo.

9. Una evaluación del programa alimentario "Desarrollo de la Educación Básica y Cuidados de Salud Preventiva" del PMA dirigido a los Ministerios de Salud y Educación de El Salvador, concluye que "no ha habido modificaciones significativas en los niveles nutricionales de la población objetivo", en un programa que atiende a nin̄os en edad escolar y mujeres embarazadas y lactantes. S. I. Sánchez, GAES/MIPLAN, mayo 1993.

10. Acevedo, Carlos. "Las Raíces Económicas de la Crisis Ecológica en Centro América", Revista Realidad, N 37, Enero-febrero, 1994.

11. OPS-OMS. Diagnóstico hidrográfico de El Salvador, 1993. Presentación de Comisión Evaluadora, Noviembre 1993. 
12. Al respecto véase el Diagnóstico de Recursos del Sector Educativo, IIH, FEPADE, UCA, el cual contiene 10 documentos que reflejan la situación del Ministerio de Educación en El Salvador; Diagnóstico del Sector Salud, un estudio similar desarrollado por el grupo ANSAL. Se ha creado recientemente una comisión interinstitucional, encargada de sugerir y operativiza los cambios a nivel de la instancia de previsión social.

13. El FIS se creo el 31 de octubre de 1990, como una unidad de derecho público descentralizada, con autonomía en la administración de su patrimonio y en el ejercicio de sus funciones, y con personalidad jurIdica propia. Inicialmente se le definió un período de vigencia de 4 años, plazo que fue extendido hasta 1997 por medio del Decreto Legislativo No. 493 del 31 de marzo del presente año.

14. La Secretaría de Reconstrucción Nacional SRN, fue creada por Decreto Ejecutivo No. 8, publicado en el Diario Oficial No. 39, tomo No. 314 de fecha 27 de febrero de 1992, como estructura administrativa adscrita a la Presidencia de la República, cuyo propósito general era ejecutar el Plan de Reconstrucción Nacional.

15. Fundaungo, Documentos de Trabajo, Serie Análisis de la Realidad Nacional 95-3, Clarence Zuvekas. "Los programas de Inversión Social en El Salvador: una evaluación de sus experiencias y opeiones paa el Furturo", p. 3

16. Sánchez, S. I. "El Salvador: reformas estructurales y lucha contra la pobre$\mathrm{za}^{\prime \prime}$. Realidad $\mathrm{N}^{\circ}$ 43, enero-febrero 1995, p. 45-46

17. Ibid. p. 46.

18. Véase la sistematización que hizo la Agencia de Cooperación Italiana. El SILOS Sur, 1993.

19. La importancia de la remesas en la economía salvadoreña puede derivarse a partir del siguiente cuadro:

El Salvador: Remesas Internacionales Indicadores Seleccionados (\%)

\begin{tabular}{|c|c|c|c|c|}
\hline Años & PIB & Ingreso Nacional & Inversion & Consumo \\
\hline 1980 & 2.3 & 2.6 & 16.6 & 1.6 \\
\hline 1981 & 4.3 & 5.0 & 31.6 & 4.6 \\
\hline 1982 & 6.6 & 7.7 & 52.6 & 8.6 \\
\hline 1983 & 8.5 & 9.9 & 72.9 & 9.1 \\
\hline 1984 & 9.1 & 10.7 & 79.1 & 9.6 \\
\hline 1985 & 9.2 & 10.9 & 76.5 & 9.5 \\
\hline 1986 & 8.8 & 10.6 & 67.0 & 9.7 \\
\hline 1987 & 10.6 & 12.3 & 77.4 & 11.2 \\
\hline 1988 & 15.2 & 17.5 & 127.0 & 16.2 \\
\hline 1989 & 15.0 & 17.0 & 119.0 & 15.8 \\
\hline
\end{tabular}

FUENTE: Sobre la base de cifras de la "Encuesta Remesas y Economía Familiar", mayo-junio 1990, y del Banco Central de Reserva de El Salvador.

Nota: los porcentajes representan el monto de las remesas como proporción de variables seleccionadas.

Tomado de: CEPAL. El Salvador. Remesas Intemacionales y Economía Familiar. Dic. 1990 
20. Síntesis de Diagnóstico del Sector Educación. IIH, FEPADE, UCA, 1994.

21. Ibid.

22. MIPLAN-GAES. "Focalización de programas de salud y nutrición para madres y riños de hogares de bajos ingresos", Mayo 1993., pág. 3

23. Serarols, MOP, 1984 P. 15-16 y MIPLAN, UIM, 1989.

24. MIPLAN, UIM, 1980.

25. MIPLAN, UIM, 1979 y 1985.

26. FUSADES, "Caracterización socio-económica de la población salvadoreña, $1989^{\prime \prime}$ 
CUADRO 1

PAIS: BI SALVADOR

TENA: GAsto PUBLICO, 1970-1992

(En Porcentajes)

\begin{tabular}{|c|c|c|c|c|c|}
\hline Ano & \begin{tabular}{|c|} 
GASTO SOCIAL/ \\
GASTO PUBLICO1//
\end{tabular} & $\begin{array}{c}\text { GASTO SALUD/ } \\
\text { GASTO PUBLICO }\end{array}$ & \begin{tabular}{|c|} 
GASTO SALUD/ \\
PIB \\
\end{tabular} & $\begin{array}{l}\text { GASTO EDUCACION/ } \\
\text { GASTO PUBLICO }\end{array}$ & $\begin{array}{l}\text { GASTO EDUCACION/ } \\
\text { PIB } \\
\end{array}$ \\
\hline 1970 & & & 1.4 & & 2.7 \\
\hline 1971 & & & 1.3 & & 3.0 \\
\hline 1972 & & & 1.3 & & 3.1 \\
\hline 1973 & 44.2 & & 1.3 & & 3.1 \\
\hline 1974 & 39.3 & 8.9 & 1.5 & 21.7 & 3.3 \\
\hline 1975 & 40.2 & 9.7 & 1.4 & 20.7 & 3.3 \\
\hline 1976 & 37.1 & 7.5 & 1.4 & 18.6 & 3.3 \\
\hline 1977 & 37.6 & 8.0 & 1.3 & 18.5 & 3.2 \\
\hline 1978 & 41.1 & 9.4 & 1.5 & 20.6 & 3.3 \\
\hline 1979 & 35.2 & 8.6 & 1.4 & 19.4 & 3.1 \\
\hline 1980 & 38.3 & 9.7 & 1.6 & 21.1 & 3.6 \\
\hline 1981 & 32.1 & 7.2 & 1.4 & 16.7 & 3.6 \\
\hline 1982 & 30.9 & 6.7 & 1.4 & 16.6 & 3.5 \\
\hline 1983 & 32.7 & 7.7 & 1.4 & 16.7 & 3.0 \\
\hline 1984 & 26.2 & 6.1 & 1.2 & 12.9 & 2.9 \\
\hline 1985 & 29.3 & 7.0 & 1.0 & 17.5 & 2.7 \\
\hline 1986 & 23.2 & 5.0 & 0.9 & 12.2 & 2.2 \\
\hline 1987 & 27.1 & 6.4 & & 16.3 & 2.1 \\
\hline 1988 & 26.5 & 5.8 & & 15.6 & 1.9 \\
\hline 1989 & 26.7 & 6.2 & & 16.1 & 1.8 \\
\hline 1990 & 23.9 & 6.0 & 1.0 & 13.5 & 1.7 \\
\hline 1991 & 27.3 & 6.5 & & 13.5 & 1.6 \\
\hline 1992 & 24.2 & 6.1 & & 12.3 & 1.5 \\
\hline
\end{tabular}

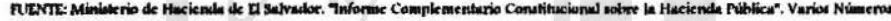

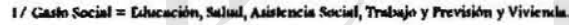


Curedro 2

PAIS: EL SALVADOR

TEMA: INDICADORES SEIECCIONADOS Y AYUDA EXTERNA, 1973-1992

(In mile de dóleres)

\begin{tabular}{|c|c|c|c|c|c|c|c|c|}
\hline \multirow[t]{2}{*}{ INDICADOTES / RAACIONES } & \multicolumn{2}{|c|}{1973.1979} & \multicolumn{2}{|c|}{$1980-1989$} & \multicolumn{2}{|c|}{$1990-1992$} & \multicolumn{2}{|l|}{ Total } \\
\hline & Monb & (\$) & Monto & (\%) & Monlo & (क्ष) & Monto & (क) \\
\hline P1B 1/ & $16,374,719.96$ & & $44,506,819.17$ & & $14,918, \$ 69.17$ & & $75,800,427.70$ & \\
\hline AYUDA DXTERA (AE) 2I & $406,671.81$ & & $3,484,158.65$ & & $1,029,862.83$ & & $1,920,693.29$ & \\
\hline AYUDA EXTERNA SOCIAL (AES) $2 /$ & $174,277.90$ & & $1,789,254,40$ & & $535,163.00$ & & $2,498,695,30$ & \\
\hline AES/AE & & 42.85 & & 51.35 & & 51.96 & & 50.78 \\
\hline PRESUPUESTO NACIONAL (FN) 3/ & $2,724,760.00$ & & $7, \bar{B} 31,000.00$ & & $2,256,480.00$ & & $12,812,240.00$ & \\
\hline PN/FIB & & 16.64 & & 17.60 & & 15.12 & & 16.90 \\
\hline GASTO PUB.DESARROLOO SOCIAL (GPDS) I/ & $1,050,080.00$ & & $2,278,480.00$ & & $566,020.00$ & & $3,328,560.00$ & \\
\hline AE/PIB & $2=2$ & 2.48 & & 7.83 & & 6.90 & & 6.49 \\
\hline AES/FiB & & 1.06 & & 4.02 & & 3.59 & & 3.30 \\
\hline GFDS/PIB & 20 & 6.41 & & 5.12 & & 3.79 & & 4.39 \\
\hline GPDS/PN & & 98.54 & & 29.10 & & 25.08 & & 25.98 \\
\hline AES/PN & & $6.40^{\circ}$ & & 22.85 & & 23.72 & & 19.50 \\
\hline AES/GDS & & 16.60 & & 78.53 & & 94.55 & & 75.07 \\
\hline
\end{tabular}

IUENTE: 1/ Revista Banco Central de Reserva, Varios Números

2/ OECD

9/ Ministerio de Hacienda de El Salvador. "Informe complementerio constitucional sobre la hacienda pública', varios números. 
CUADRO No. 3

PAIS: Q SALVADOR

TEMA: AYUDA EXTENA, 1979-1992

(En millones de dóleres)

\begin{tabular}{|c|c|c|c|}
\hline ANOS & FIB 1/ & $\begin{array}{c}\text { AYUDA } \\
\text { DXTENA 2/ }\end{array}$ & $\begin{array}{c}\text { AE/PB } \\
\%\end{array}$ \\
\hline 1979 & & $7,969.00$ & \\
\hline 1974 & $1,577,483.32$ & $40,986.00$ & 2.60 \\
\hline 1975 & $1,791,074.80$ & $63,568.39$ & $\mathbf{5 . 3 5}$ \\
\hline 1976 & $2,282,351.64$ & 39,061.91 & 1.71 \\
\hline 1977 & $2,866,822.00$ & $48,879.57$ & $1.7 \mathrm{I}$ \\
\hline 1978 & $9,076,862.80$ & $199,22.3 .75$ & 4.52 \\
\hline 1979 & $3,447,48-4.80$ & $66,983.19$ & 1.94 \\
\hline 1980 & $3,377,+40.00$ & 138,990.85 & 3.87 \\
\hline 1981 & $3,518,280.12$ & $152,866.58$ & 4.34 \\
\hline 1982 & $3,521,362.04$ & $924,244.87$ & $9.2 \mathrm{I}$ \\
\hline 198.3 & $3,901,640.08$ & $260,273.10$ & 6.67 \\
\hline 1984 & $4,446,560.12$ & $314,748.78$ & 7.08 \\
\hline 198.5 & $5,732.320 .00$ & $503,842.03$ & 8.79 \\
\hline 1986 & $3,962,380.00$ & $311,182.87$ & 7.87 \\
\hline 1987 & $4,628,120.00$ & $571,475.24$ & I2.35 \\
\hline 1988 & $5,473,160.00$ & $587,937.42$ & 10.74 \\
\hline 19B9 & $5,755,357.14$ & $319,196.91$ & 5.55 \\
\hline 1990 & $5,402,236.84$ & $907,431.95$ & 5.69 \\
\hline 1991 & $3,974,000.00$ & $443,874.83$ & 7.49 \\
\hline 1992 & $3,542,652.33$ & $278,556.05$ & 7.86 \\
\hline LES & $74,467,788.03$ & $4,920,693.29$ & G.G1 \\
\hline
\end{tabular}

תIETTE: 1/Banco Central de Reserva de EJ Salvadur 2/OECD 
CUADRO 4

EL SALVADOR: FUUJOS DE AYUDA EXTERNA AL SECTOR DE SERVICIOS SOCLIES Y Y COMUNTTARIOS POR SUBSECTOR 1973-1992 (MILES DE DOLARES)

\begin{tabular}{|c|c|c|c|c|c|c|c|c|}
\hline \multirow[b]{2}{*}{ SUBSECTOR } & \multicolumn{2}{|c|}{$73-79$} & \multicolumn{2}{|c|}{80.89} & \multicolumn{2}{|c|}{$90-92$} & \multicolumn{2}{|c|}{ Tola] } \\
\hline & Monto & (\%) & Monto & $($ (x) & Monto & (\%) & Monlo & $(x)$ \\
\hline $\begin{array}{l}\text { EDUCACION } \\
\text { No. proyectos }\end{array}$ & $\begin{array}{c}67,896.4 \\
12.0\end{array}$ & 38.9 & $\begin{array}{c}73,003.5 \\
26.0\end{array}$ & 4.1 & $\begin{array}{c}45,091.2 \\
13.0\end{array}$ & 8.4 & $\begin{array}{c}183,931.1 \\
51.0\end{array}$ & 7.4 \\
\hline $\begin{array}{l}\text { SALUD } \\
\text { No. proyectos }\end{array}$ & $\begin{array}{c}15,422.4 \\
3.0\end{array}$ & 8.8 & $\begin{array}{c}211,259.6 \\
55.0\end{array}$ & 11.8 & $\begin{array}{l}35,916.5 \\
17.0\end{array}$ & 6.7 & $\begin{array}{l}262,598.5 \\
75.0\end{array}$ & 10.5 \\
\hline $\begin{array}{l}\text { VTVENDA Y DESARROLLO URBANO } \\
\text { No. proyeclos }\end{array}$ & $\begin{array}{c}12,700.0 \\
2.0\end{array}$ & 7.3 & $\begin{array}{c}91,398.7 \\
8.0\end{array}$ & 5.1 & $\begin{array}{c}1,243.1 \\
1.0\end{array}$ & 0.2 & $\begin{array}{c}105,341.8 \\
11.0\end{array}$ & 4.2 \\
\hline $\begin{array}{l}\text { SANEAMIENTO Y MEDIO AMBIENTE } \\
\text { No. proyectos }\end{array}$ & $\begin{array}{c}35,587.1 \\
4.0\end{array}$ & 20.4 & $\begin{array}{c}218,124.4 \\
\text { B.0 }\end{array}$ & 12.2 & $\begin{array}{c}29,220.0 \\
3.0\end{array}$ & 5.5 & $\begin{array}{c}282,931.5 \\
15.0\end{array}$ & 11.3 \\
\hline $\begin{array}{l}\text { PROGRAMAS RURALES } \\
\text { No. proyeclos }\end{array}$ & $\begin{array}{c}13,200.0 \\
1.0\end{array}$ & 7.6 & $\begin{array}{c}2,637.5 \\
2.0\end{array}$ & 0.1 & $\begin{array}{c}4,075.0 \\
2.0\end{array}$ & 0.8 & $\begin{array}{c}19,912.5 \\
5.0\end{array}$ & 0.8 \\
\hline $\begin{array}{l}\text { AYUDA ALIMENTARIA } \\
\text { No. proyectos }\end{array}$ & $\begin{array}{c}1,502.9 \\
4.0\end{array}$ & 0.9 & $\begin{array}{c}400,347.8 \\
33.0\end{array}$ & 22.4 & $\begin{array}{c}91,806.5 \\
6.0\end{array}$ & 17.2 & $\begin{array}{c}493,657.2 \\
43.0\end{array}$ & 19.8 \\
\hline $\begin{array}{l}\text { DESASTRES Y EMIRGENCLAS } \\
\text { No. proyeelos }\end{array}$ & $\begin{array}{c}279.1 \\
2.0\end{array}$ & 0.2 & $\begin{array}{c}221,176.7 \\
79.0 \\
\end{array}$ & 12.4 & $\begin{array}{c}15,699.3 \\
20.0 \\
\end{array}$ & 2.9 & $\begin{array}{c}237,155.0 \\
101.0\end{array}$ & 9.5 \\
\hline $\begin{array}{l}\text { OTROS PROGRAMAS SOCIALLS } \\
\text { No. proyectos }\end{array}$ & & 0.0 & $\begin{array}{c}54,739.5 \\
23.0 \\
\end{array}$ & 9.1 & $\begin{array}{c}55,331.8 \\
9.0 \\
\end{array}$ & 10.3 & $\begin{array}{c}110,071.3 \\
32.0\end{array}$ & 4.4 \\
\hline $\begin{array}{l}\text { SUB-TOTAL FROGRAMAS SOCIALES } \\
\text { No. proyeclos }\end{array}$ & $\begin{array}{c}146,527.8 \\
28.0\end{array}$ & 84.1 & $\begin{array}{c}1,272,687.6 \\
234.0\end{array}$ & 71.1 & \begin{tabular}{|c|}
$278,383.4$ \\
71.0 \\
\end{tabular} & 52.0 & $\begin{array}{c}1,697,598.8 \\
339.0 \\
\end{array}$ & 67.9 \\
\hline $\begin{array}{l}\text { PROGRAMAS PUPUCOS NO SOCIALES } \\
\text { No. proyeclos }\end{array}$ & $\begin{array}{c}27,750.0 \\
11.0 \\
\end{array}$ & 15.9 & $\begin{array}{c}516,566.8 \\
59.0 \\
\end{array}$ & 28.9 & \begin{tabular}{|c|}
$256,779.6$ \\
36.0 \\
\end{tabular} & 48.0 & $\begin{array}{c}801,096.4 \\
106.0\end{array}$ & 32.1 \\
\hline $\begin{array}{l}\text { TOTAL } \\
\text { No. proyectos }\end{array}$ & $\begin{array}{c}174,277.9 \\
39.0\end{array}$ & 100.0 & $\begin{array}{l}1,789,254.4 \\
293.0\end{array}$ & 100.0 & $\begin{array}{c}535,163.0 \\
107.0\end{array}$ & 100.0 & $\begin{array}{c}2,498,695.2 \\
439.0\end{array}$ & 100.0 \\
\hline
\end{tabular}

Fuenle: OECD

Cilculog: FEDESARROLO 
Cundro No. 5

Pais El Salvador

Tema: Indicadores seleccionados y ayuda externa 1973-1992

(Porcentajes)

\begin{tabular}{|c|c|c|c|c|}
\hline & $1973-1979$ & $1980-1989$ & 1990-1992 & TOTAL \\
\hline \multicolumn{5}{|l|}{ AE DESUBSECTOR/AES } \\
\hline Educación/AES & 38.92 & 4.08 & 8.43 & $\mathbf{7 . 4 4}$ \\
\hline Salud/AES & 8.85 & $11.8 \mathrm{I}$ & 6.71 & 10.51 \\
\hline Viv. y Des. Urbano/AES & 7.29 & 5.11 & 0.23 & 4.22 \\
\hline San. y Med. Amb./AES & 20.42 & 12.19 & 5.46 & 11.32 \\
\hline Programas Rurales/AES & $\mathbf{7 . 5 7}$ & 0.15 & 0.76 & 0.80 \\
\hline Ayuda Alimentaria AES & 0.86 & 22.38 & 17.15 & 19.76 \\
\hline Desustres y Emerg./AES & 0.16 & 12.36 & 2.93 & 9.49 \\
\hline Otros prog. Soc./AES & - & 3.06 & 10.94 & 4.41 \\
\hline SUBTOTAL. PROGR. SOC./AES & 84.08 & 71.13 & 52.02 & 67.94 \\
\hline Prog. púb. no sociales/AES & 15.92 & 28.87 & 47.98 & 32.06 \\
\hline \multicolumn{5}{|l|}{ AE. DE SUBSECTOR/MN } \\
\hline Educación/PN & 2.49 & 0.93 & 2.00 & 1.45 \\
\hline Salud/PN & 0.57 & 2.70 & 1.59 & 2.05 \\
\hline Viv. y Des. Urbano/PN & 0.47 & 1.17 & 0.06 & 0.82 \\
\hline Sen. y Med. Amb./PN & 1.31 & 2.79 & 1.29 & 2.21 \\
\hline Programas Rurales/FN & 0.48 & 0.03 & 0.18 & 0.16 \\
\hline Ayuda alimentaria/PN & 0.06 & 5.11 & 4.07 & 3.85 \\
\hline Desastres y Emerg./PN & 0.01 & 2.82 & 0.70 & 1.85 \\
\hline Otros prog. Soc./PN & - & 0.70 & 2.45 & 0.86 \\
\hline SUBTOTAL PROGR, SOC./PN & 5.38 & 16.25 & 12.34 & 13.25 \\
\hline Prog. púb. no sociales/PN & 1.02 & 6.60 & 11.38 & 6.25 \\
\hline \multicolumn{5}{|l|}{ AE DE SUBSECTOR/GPDS } \\
\hline Educación/GPDS & 6.46 & 3.20 & 7.97 & 5.59 \\
\hline Salud/GPDS & 1.47 & 9.27 & 6.36 & 7.80 \\
\hline Viv. y Des. Urbano/GPDS & 1.21 & 4.01 & 0.22 & 3.16 \\
\hline San. y Med. Amb./GPDS & 3.39 & 9.57 & 5.16 & 8.50 \\
\hline Programas Rurales/GPDS & 1.26 & 0.12 & 0.72 & 0.60 \\
\hline Ayuda Alimentaria/GPDS & 0.14 & 17.57 & 16.22 & 14.83 \\
\hline Desastres y Emerg./GPDS & 0.03 & 9.71 & 2.77 & 7.12 \\
\hline Otros prog. Soc./GPDS & - & 2.40 & 9.78 & 3.31 \\
\hline SUBTOTAL FROG. SOC./GIDS & 13.95 & 55.66 & 49.18 & 51.00 \\
\hline Prog. púb. no sociales/GPDS & 2.64 & 22.67 & 45.37 & 24.07 \\
\hline
\end{tabular}

Fuente: Revisia Banco Central de Reserva. Varios números. 
Cuadro No. 6

RL SALVADOR: FUUOS DE AYUDA EXTERNA AL SECTOR DE SERVICIOS SOCLLLS Y COMUNTARKO FOR TIRO Y SUESECTOK 197S-1992 (MILSS DE DOLAREs)

\begin{tabular}{|c|c|c|c|c|c|c|c|c|}
\hline & \multicolumn{2}{|c|}{$73-79$} & \multicolumn{2}{|c|}{ 80-89 } & \multicolumn{2}{|c|}{$90-92$} & \multicolumn{2}{|c|}{ TOTAL } \\
\hline & Monto & (\%) & Monto & (\%) & Monto & (\%) & Monto & $\mathbf{2}$ \\
\hline \multicolumn{9}{|l|}{ Forenec.Bruta de Ceppitel $66.34 \%$} \\
\hline $\begin{array}{l}\text { ZDUCACION } \\
\text { No. de proyectias }\end{array}$ & $\begin{array}{r}67,767.4 \\
10.0 \\
\end{array}$ & 39.5 & $\begin{array}{r}71,572.1 \\
19.0 \\
\end{array}$ & 6.6 & $\begin{array}{r}29006.3 \\
10.0 \\
\end{array}$ & 7.1 & $168,345.8$ & 10.2 \\
\hline $\begin{array}{l}\text { SALUn } \\
\text { No. de proyectos }\end{array}$ & $\begin{array}{r}15,166.4 \\
2.0 \\
\end{array}$ & 8.8 & $\begin{array}{r}206.567 .6 \\
49.0 \\
\end{array}$ & \$9.1 & $\begin{array}{r}34.716 .5 \\
15.0 \\
\end{array}$ & 8.5 & 256.450 .5 & 15.5 \\
\hline $\begin{array}{l}\text { VNIENDA Y DESARROLLO URBANO } \\
\text { No.de proyecto: }\end{array}$ & $\begin{array}{r}12,700.0 \\
2.0 \\
\end{array}$ & 7.4 & $\begin{array}{r}91.398 .7 \\
8.0 \\
\end{array}$ & 8.5 & $\begin{array}{r}1,243.1 \\
1.0 \\
\end{array}$ & 0.3 & 108341.8 & 6.4 \\
\hline $\begin{array}{l}\text { SANEAMIENTO Y MEDHO AMBIENTE } \\
\text { No. de proyection }\end{array}$ & $\begin{array}{r}35.565 .2 \\
3.0 \\
\end{array}$ & 20.7 & $\begin{array}{r}218,124.4 \\
8.0 \\
\end{array}$ & 20.2 & $\begin{array}{r}29220.0 \\
3.0\end{array}$ & 7.2 & $282,909,6$ & 17.1 \\
\hline $\begin{array}{l}\text { PROGRAMUS KLILALAS } \\
\text { No, de proyection }\end{array}$ & $\begin{array}{r}13.200 .0 \\
1.0 \\
\end{array}$ & 7.7 & $\begin{array}{r}2,637.5 \\
2.0 \\
\end{array}$ & 0.2 & $\begin{array}{r}4.075 .0 \\
2.0 \\
\end{array}$ & 1.0 & $19,912.5$ & 1.2 \\
\hline $\begin{array}{l}\text { OTROS PROGRAMAS SOCLIALS } \\
\text { No. de proyectos }\end{array}$ & & $\boldsymbol{\infty}, \boldsymbol{0}$ & $\begin{array}{r}54,580.7 \\
21.0 \\
\end{array}$ & 5.0 & $\begin{array}{r}54892.7 \\
8.0 \\
\end{array}$ & 13.5 & $109,273.4$ & 6.6 \\
\hline $\begin{array}{l}\text { SUBTOTAL DE PROGRAMAS SOCLIALX' } \\
\text { No. de Proyectos }\end{array}$ & $\begin{array}{r}144.999 .0 \\
18.0 \\
\end{array}$ & $84: 2$ & $\begin{array}{r}644,681.1 \\
107.0 \\
\end{array}$ & 59.7 & $\begin{array}{r}153.153 .6 \\
39.0 \\
\end{array}$ & 97.6 & 942,253.7 & 56.8 \\
\hline 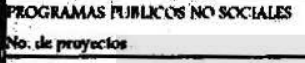 & $\begin{array}{r}27,184.9 \\
6.0 \\
\end{array}$ & 15.8 & $\begin{array}{r}434,572.1 \\
42.0 \\
\end{array}$ & 10.5 & $\begin{array}{r}253,668.0 \\
5 . \quad 26.0 \\
\end{array}$ & 62.4 & $715,425.0$ & 43.2 \\
\hline $\begin{array}{l}\text { Toral } \\
\text { No. de proyectos }\end{array}$ & $\begin{array}{r}171,585.9 \\
24.0\end{array}$ & 100.0 & $\begin{array}{r}1079,253.2 \\
149.0\end{array}$ & 100.0 & $\begin{array}{r}406,821.6 \\
65.0\end{array}$ & 100.0 & 1.657 .558 .7 & 100.0 \\
\hline \multicolumn{5}{|l|}{ No formución Dratu de Capienl 4.5\% } & & . & + & \\
\hline $\begin{array}{l}\text { SDUCACION } \\
\text { No: ile proyectos }\end{array}$ & & & $\begin{array}{r}847.2 \\
6.0 \\
\end{array}$ & 1.0 & $\begin{array}{r}15,993.0 \\
2.0 \\
\end{array}$ & $\because 1.7$ & $16 \$ 40.2$ & 15.7 \\
\hline $\begin{array}{l}\text { SAuid } \\
\text { No. de proyoctos }\end{array}$ & & 1 & $\begin{array}{r}+572.0 \\
5.0\end{array}$ & 3.2 & $\begin{array}{r}1200.0 \\
2.0 \\
\end{array}$ & 6.1 & $9,772.0$ & 5.4 \\
\hline \multicolumn{9}{|l|}{$\begin{array}{l}\text { VNIENDA Y OESARECTLIO URBANO } \\
\text { Na. Le proyectos }\end{array}$} \\
\hline $\begin{array}{l}\text { SANEAMIENTO Y MEDHO AMBIENTE } \\
\text { No. de proyeclos }\end{array}$ & $\begin{array}{r}21.9 \\
1.0 \\
\end{array}$ & 6f.0. & & 0.0 & & 0.0 & 21.9 & 0.0 \\
\hline $\begin{array}{l}\text { PaCKGRAMUS RURALS: } \\
\text { Jo. we proyoclos }\end{array}$ & & 0.0 & & 0.0 & & 0.0 & 0.0 & \\
\hline $\begin{array}{l}\text { OTROS PROGRAMAS SCSCLLES } \\
\text { No. de proyextios }\end{array}$ & & 0.0 & $\begin{array}{r}330.0 \\
1.0 \\
\end{array}$ & 0.4 & & & 550.0 & 0.3 \\
\hline 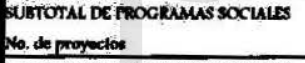 & $\begin{array}{r}21.9 \\
1.0 \\
\end{array}$ & 06.0 & $\begin{array}{r}5,749.2 \\
12.0 \\
\end{array}$ & 6.6 & $\begin{array}{r}17,195,0 \\
4.0 \\
\end{array}$ & 87.8 & $22, \times 44.1$ & 21.4 \\
\hline 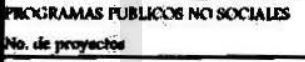 & $\begin{array}{r}11.3 \\
1.0 \\
\end{array}$ & $\mathbf{5 . 0}$ & $\begin{array}{r}81,994.7 \\
17.0 \\
\end{array}$ & 98.4 & $\begin{array}{r}2.889 .1 \\
\because 7.0 \\
\end{array}$ & 12.3 & $84,595.1$ & 78.6 \\
\hline $\begin{array}{l}\text { MoTAL } \\
\text { Na. de proyectos }\end{array}$ & $\begin{array}{r}33.2 \\
2.0\end{array}$ & 100.0 & $\begin{array}{r}87.748 .2 \\
29.0\end{array}$ & 100.0 & $\begin{array}{r}19.582 .1 \\
11.0\end{array}$ & 100.0 & $107,359.2$ & 1000 \\
\hline
\end{tabular}

Rucate DeCD

CALCULOS: FiDesartotu? 
Cundro'No. 6 (Comtinunción)

El. SALVADOR: HUJOS DE AYUDA EXTELNA AL SECTOR DE SERYYCIOS SOCLLES Y COMUNTTANOS FOR TIRO Y SUESECTOR 1973-1992 (MULES DE DOLARS)

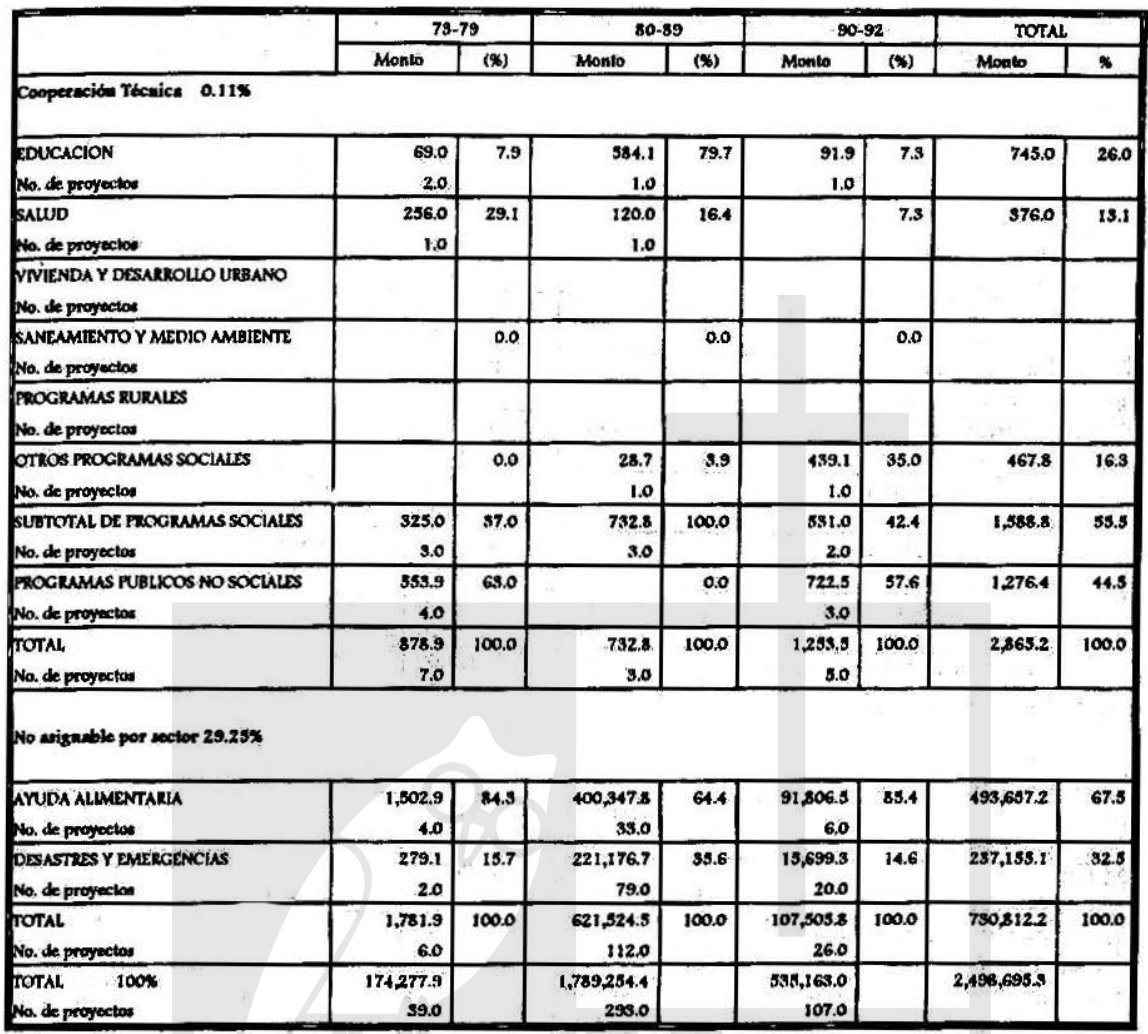

TUENTE: DECD

CAlculos: renesunumolo 
Cundro No. 7

EL SALVADOR: FUJOS DE AYUDA EXTERNA AL SECTOR DE SERVICIOS

SOCLALES Y COMUNTTARUOS

POR DONANTE Y SUBSECTOR 1973-1992

(MILES DE DOLARES)

\begin{tabular}{|c|c|c|c|c|c|}
\hline DONANTE/SUBSECTOR & $73-79$ & $80-89$ & $90-92$ & Total & \% \\
\hline $\begin{array}{l}\text { BILATYRAL } \\
\text { Estados Unidos }\end{array}$ & & & & & 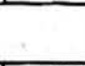 \\
\hline $\begin{array}{l}\text { EDUCACION } \\
\text { No. de proyectos }\end{array}$ & $\begin{array}{r}7,550.00 \\
3.00\end{array}$ & $\begin{array}{r}72,090.00 \\
20.00\end{array}$ & $\begin{array}{r}29,727.00 \\
8.00\end{array}$ & $109,367.00$ & 6.85 \\
\hline $\begin{array}{l}\text { SALUD } \\
\text { No. de proyectos }\end{array}$ & & $\begin{array}{r}140,919.00 \\
44.00 \\
\end{array}$ & $\begin{array}{r}31,736.00 \\
13.00 \\
\end{array}$ & $172,655.00$ & 10.82 \\
\hline $\begin{array}{l}\text { VIVIENDA Y DESARROLLO URBANO } \\
\text { No. de proyectos }\end{array}$ & & $\begin{array}{r}1,000.00 \\
1.00 \\
\end{array}$ & & $1,000.00$ & 0.06 \\
\hline $\begin{array}{l}\text { SANEAMIENTO Y MEDIO AMBIENTE } \\
\text { No. de proyectos }\end{array}$ & & $\begin{array}{r}18,744.00 \\
3.00 \\
\end{array}$ & $\begin{array}{r}4,220.00 \\
2.00 \\
\end{array}$ & $22,964.00$ & 1.44 \\
\hline $\begin{array}{l}\text { PROGRAMAS RURALES } \\
\text { No. de proyectos } \\
\end{array}$ & & $\begin{array}{r}2,480.00 \\
1.00 \\
\end{array}$ & $\begin{array}{r}4,075.00 \\
2.00 \\
\end{array}$ & $6,555.00$ & 0.41 \\
\hline $\begin{array}{l}\text { AYUDA ALMENTARIA } \\
\text { No. de proyectos }\end{array}$ & $\begin{array}{r}1,025.00 \\
2.00 \\
\end{array}$ & $\begin{array}{r}393,650.00 \\
25.00 \\
\end{array}$ & $\begin{array}{r}91,650.00 \\
5.00 \\
\end{array}$ & $486,325.00$ & 30.47 \\
\hline $\begin{array}{l}\text { DESASTRES Y EMERGENCIAS } \\
\text { No. de proyectos } \\
\end{array}$ & & $\begin{array}{r}158,387.00 \\
9.00 \\
\end{array}$ & $\begin{array}{r}10,427.00 \\
3.00 \\
\end{array}$ & $168,814.00$ & 10.58 \\
\hline $\begin{array}{l}\text { OTROS PROGRAMAS SOCINLES } \\
\text { No. de proyectos }\end{array}$ & & $\begin{array}{r}53,400.00 \\
20.00 \\
\end{array}$ & $\begin{array}{r}24,689.00 \\
3.00 \\
\end{array}$ & $78,089.00$ & 4.89 \\
\hline $\begin{array}{l}\text { SUBTOTAL. DE PROGRAMAS SOCIALES } \\
\text { No. de proyectos }\end{array}$ & $\begin{array}{r}8,575.00 \\
5.00 \\
\end{array}$ & $\begin{array}{r}840,670.00 \\
123.00 \\
\end{array}$ & $\begin{array}{r}196,524.00 \\
36.00\end{array}$ & $1,045,769.00$ & 65.51 \\
\hline $\begin{array}{l}\text { PROGRAMAS PUBLICOS NO SOCIALES } \\
\text { No. de proyectos }\end{array}$ & $\begin{array}{r}2,300.00 \\
1.00 \\
\end{array}$ & $\begin{array}{r}493,294.00 \\
45.00 \\
\end{array}$ & $\begin{array}{r}54,962.00 \\
17.00 \\
\end{array}$ & $550,556.00$ & 34.49 \\
\hline $\begin{array}{l}\text { TOTAL } \\
\text { No. de proyectos }\end{array}$ & $\begin{array}{r}10,875.00 \\
6.00 \\
\end{array}$ & $\begin{array}{r}1,333,964.00 \\
168.00 \\
\end{array}$ & $\begin{array}{r}251,486.00 \\
53.00 \\
\end{array}$ & $1,596,325.00$ & 100.00 \\
\hline \multicolumn{6}{|l|}{ Paises Nórdicos y Canadí } \\
\hline $\begin{array}{l}\text { EDUCACION } \\
\text { No. de proyectos }\end{array}$ & $\begin{array}{r}1,717.40 \\
3.00 \\
\end{array}$ & $\begin{array}{r}913.50 \\
6.00 \\
\end{array}$ & $\begin{array}{r}129.60 \\
1.00 \\
\end{array}$ & $2,760.50$ & 4.81 \\
\hline $\begin{array}{l}\text { SALUD } \\
\text { No. de proyectos }\end{array}$ & & $\begin{array}{r}3,267.10 \\
4.00 \\
\end{array}$ & $\begin{array}{r}1,004.50 \\
2.00 \\
\end{array}$ & $4,271.60$ & 7.44 \\
\hline $\begin{array}{l}\text { VIVIENDA Y DESARROLLO URBANO } \\
\text { No. de proyectos }\end{array}$ & & $\begin{array}{r}77.19 \\
1.00 \\
\end{array}$ & & 77.19 & 0.13 \\
\hline $\begin{array}{l}\text { SANEAMIENTO Y MEDIO AMBIENTE } \\
\text { No. de proyectos }\end{array}$ & $\begin{array}{r}887.10 \\
2.00 \\
\end{array}$ & & & 887.10 & 1.55 \\
\hline $\begin{array}{l}\text { PROGRAMAS RURALES } \\
\text { No. de proyectos }\end{array}$ & & $\begin{array}{r}157.49 \\
1.00 \\
\end{array}$ & & 157.49 & 0.27 \\
\hline $\begin{array}{l}\text { AYUDA AUMENTARIA } \\
\text { No. de proyectos } \\
\end{array}$ & & $\begin{array}{r}1,655.45 \\
3.00 \\
\end{array}$ & & $1,655.45$ & 2.88 \\
\hline $\begin{array}{l}\text { DESASTRES Y EMERGENCIAS } \\
\text { No. de proyectos }\end{array}$ & $\begin{array}{r}279.05 \\
2.00 \\
\end{array}$ & $\begin{array}{r}30,250.62 \\
45.00 \\
\end{array}$ & $\begin{array}{r}4,427.91 \\
13.00 \\
\end{array}$ & $34,957.58$ & 60.91 \\
\hline $\begin{array}{l}\text { OTROS PROGRAMAS SOCIALES } \\
\text { No. de proyectos }\end{array}$ & & $\begin{array}{r}1,339.47 \\
3.00 \\
\end{array}$ & $\begin{array}{r}4,518.34 \\
3.00 \\
\end{array}$ & $5,857.81$ & 10.21 \\
\hline $\begin{array}{l}\text { SUBTOOTAL DE PROGRAMUS SOCINLES } \\
\text { No. de proyectos }\end{array}$ & $\begin{array}{r}2,883.56 \\
7.00 \\
\end{array}$ & $\begin{array}{r}37,660.76 \\
63.00 \\
\end{array}$ & $\begin{array}{r}10,080.36 \\
3.00 \\
\end{array}$ & $50,624.68$ & 88.20 \\
\hline $\begin{array}{l}\text { PROGRAMAS PUBLICOS NO SOCIALES } \\
\text { No. de proyectos }\end{array}$ & $\begin{array}{r}158.82 \\
4.00 \\
\end{array}$ & $\begin{array}{r}3,265.22 \\
6.00 \\
\end{array}$ & $\begin{array}{r}3,366.20 \\
10.00 \\
\end{array}$ & $6,770.24$ & 11.80 \\
\hline $\begin{array}{l}\text { TOTAL } \\
\text { No. de proyectos }\end{array}$ & $\begin{array}{r}3,022.40 \\
11.00 \\
\end{array}$ & $\begin{array}{r}40,926.00 \\
69.00 \\
\end{array}$ & $\begin{array}{r}13,446.60 \\
29.00 \\
\end{array}$ & $57,395.00$ & 100.00 \\
\hline
\end{tabular}


EL SALVADOR: RUJOS DE AYUDA EXTLRNA AL, SECTOR DE SERVICIOS SOCIALES Y COMUNITARIOS

POR DONANTE Y SUBSECTOR 1973-1992

(MILES DE DOLARES)

\begin{tabular}{|c|c|c|c|c|c|}
\hline DONANTE/SUBSECTOR & $73-79$ & Bo-89 & $90-92$ & TOTAL & \% \\
\hline \multicolumn{6}{|l|}{ Europu Central y Occidental } \\
\hline EDUCACION & 29.00 & & 91.90 & 120.90 & 0.11 \\
\hline No. de proyectos & 1.00 & & 1.00 & & \\
\hline SALUD & 166.40 & $39,444.60$ & 150.00 & $39,761.00$ & $\mathbf{3 7 . 3 9}$ \\
\hline No. de proyectos & 1.00 & 5.00 & $1 . \infty$ & & \\
\hline $\begin{array}{l}\text { VIVIENDA Y DESARROLLO URBANO } \\
\text { No. de proyectos }\end{array}$ & & $\begin{array}{r}13,221.54 \\
3.00\end{array}$ & & $13,221.54$ & 12.43 \\
\hline $\begin{array}{l}\text { SANEAMIENTO Y MEDIO AMBIENTE } \\
\text { No. de proyectos }\end{array}$ & & $\begin{array}{r}7,973.20 \\
2.00\end{array}$ & & $7,973.20$ & 7.50 \\
\hline $\begin{array}{l}\text { PROGRAMAS RURALES } \\
\text { No, de proyectos. }\end{array}$ & & & & 0.00 & 0.00 \\
\hline $\begin{array}{l}\text { AYUDA ALIMENTARIA } \\
\text { No. de proyectos }\end{array}$ & & $\begin{array}{r}1,862.32 \\
3.00\end{array}$ & $\begin{array}{r}156.51 \\
1.00\end{array}$ & $2,018.83$ & 1.90 \\
\hline DESASTRES Y EMERGENCIAS & & $28,844.57$ & 844.34 & $29,688.91$ & 27.92 \\
\hline $\begin{array}{l}\text { No. de proyectos } \\
\text { OTROS PROGRAMAS SOCIALES }\end{array}$ & & 20.00 & 4.00 & & \\
\hline $\begin{array}{l}\text { OTROS PROGRAMAS SOCIALES } \\
\text { No. de proyoctos }\end{array}$ & - & & & 0.00 & 0.00 \\
\hline $\begin{array}{l}\text { SUBTTOTAL DE FROGRAMAS SOCIALES } \\
\text { No. de proyectos }\end{array}$ & $\begin{array}{r}195.42 \\
2.00 \\
\end{array}$ & $\begin{array}{r}91,346.22 \\
33.00 \\
\end{array}$ & $\begin{array}{r}1,242.74 \\
7.00 \\
\end{array}$ & $92,784.38$ & 87.24 \\
\hline PROGRAMAS PUBUICOS NO SOCIALES & 11.20 & $5,321.45$ & $8,237.38$ & $13,570.03$ & 12.76 \\
\hline No. de proyectos & 1.00 & 3.00 & 4.00 & & \\
\hline TOTAL & 206.60 & $96,667.70$ & $9,480.10$ & $106,354,40$ & 100.00 \\
\hline \multicolumn{6}{|l|}{ Japón } \\
\hline DDUCACION & & & 742.70 & 742.70 & 4.49 \\
\hline No. de proyectos & & & 2.00 & & \\
\hline SAUD & & 628.90 & $3,026.00$ & $3,654.90$ & 22.08 \\
\hline No. de proyectos & & 1.00 & 1.00 & & \\
\hline VIVILNDA Y DESARROLLO URBANO & & & $\begin{array}{r}1,243.09 \\
1,00\end{array}$ & $1,243.09$ & 7.51 \\
\hline No. de proyectos & & & 1.00 & & \\
\hline $\begin{array}{l}\text { SANEAMIENTO Y MEDIO AMBIENTE } \\
\text { No. de proyectos }\end{array}$ & & $\begin{array}{r}4,407.20 \\
1.00 \\
\end{array}$ & & $4,407.20$ & 26.62 \\
\hline $\begin{array}{l}\text { PROGRAMAS RURALES } \\
\text { No. de proyectos }\end{array}$ & & & & 0.00 & 0.00 \\
\hline $\begin{array}{l}\text { AYUDA AIIMENTARIA } \\
\text { No. de proyectos }\end{array}$ & & $\begin{array}{r}2,373.89 \\
1.00 \\
\end{array}$ & & $2,373.89$ & 14.34 \\
\hline $\begin{array}{l}\text { DESASTRES Y EMIRRGENCIAS } \\
\text { No. de proyectos }\end{array}$ & & $\begin{array}{r}2,224.02 \\
3.00\end{array}$ & & $2,224.02$ & 13.44 \\
\hline $\begin{array}{l}\text { OTROS PROGRAMAS SOCLAIES } \\
\text { No. de proyectos }\end{array}$ & & & $\begin{array}{r}124.45 \\
2.00 \\
\end{array}$ & 124.45 & 0.75 \\
\hline $\begin{array}{l}\text { SUBTO'TAL DE PROGRAMAS SOCIAIIS } \\
\text { No. de proyectoo }\end{array}$ & 0.00 & $\begin{array}{r}9,634.02 \\
6.00 \\
\end{array}$ & $\begin{array}{r}5,136.27 \\
6.00 \\
\end{array}$ & $14,770.29$ & 89.23 \\
\hline $\begin{array}{l}\text { RROGRAMAS FUBLICOS NO SOCIAIISS } \\
\text { No. de proyectos }\end{array}$ & & $\begin{array}{r}1,782.61 \\
1.00\end{array}$ & & $1,782.61$ & 10.77 \\
\hline $\begin{array}{l}\text { TOTAL. } \\
\text { No. de proyectoes }\end{array}$ & $\begin{array}{l}0.00 \\
0.00\end{array}$ & $\begin{array}{r}11,116.60 \\
7.00\end{array}$ & $\begin{array}{r}5,136.30 \\
6.00\end{array}$ & $16,552.90$ & 100.00 \\
\hline
\end{tabular}


Cuadro No. 7 (Continuación)

EL. SALVADOR: FUJOS DE AYUDA EXTERNA AL SECTOR DE

SERVICIOS SOCIALES Y COMUNITARIOS

POR DONANTE Y SUBSECTOR 1973-1992 (MILES DE DOLARES)

\begin{tabular}{|c|c|c|c|c|c|}
\hline DONANTE/SUBSECTOR & $73-79$ & $80-89$ & $90-92$ & TOTAL & $\%$ \\
\hline Minitilnteral & & & & & \\
\hline $\begin{array}{l}\text { XDUCACION } \\
\text { No. de proyectos }\end{array}$ & $\begin{array}{r}58,540.00 \\
5.00\end{array}$ & & $\begin{array}{r}14,400.00 \\
1.00\end{array}$ & $72,940.00$ & 10.10 \\
\hline $\begin{array}{l}\text { SALUD } \\
\text { No. de proyectos }\end{array}$ & $\begin{array}{r}15,256.00 \\
2.00 \\
\end{array}$ & $\begin{array}{r}27,000.00 \\
1.00\end{array}$ & & $42,256.00$ & 5.85 \\
\hline $\begin{array}{l}\text { VIVIENDA Y DESARROULO URBANO } \\
\text { No. de proyectos }\end{array}$ & $\begin{array}{r}12,700.00 \\
2.00 \\
\end{array}$ & $\begin{array}{r}77,100.00 \\
3.00 \\
\end{array}$ & & $89,800.00$ & 12.44 \\
\hline $\begin{array}{l}\text { SANEAMIENTO Y MEDIO AMBIENTE } \\
\text { No. de proyectos }\end{array}$ & $\begin{array}{r}34,700.00 \\
2.00\end{array}$ & $\begin{array}{r}187,000.00 \\
2.00\end{array}$ & $\begin{array}{r}25,000.00 \\
1.00\end{array}$ & $246,700.00$ & $\$ 4.17$ \\
\hline $\begin{array}{l}\text { PROGRAMAS RURALIS } \\
\text { No. de proyectos }\end{array}$ & $\begin{array}{r}13,200.00 \\
1.00\end{array}$ & & & $13,200.00$ & 1.83 \\
\hline $\begin{array}{l}\text { AYUDA ALIMENTARIA } \\
\text { No. de proyectos }\end{array}$ & $\begin{array}{r}477.86 \\
2.00\end{array}$ & $\begin{array}{r}806.18 \\
1.00\end{array}$ & & $1,284.04$ & 0.18 \\
\hline $\begin{array}{l}\text { DESASTRES Y EMERGENCLIAS } \\
\text { No. de proyectos }\end{array}$ & & $\begin{array}{r}1,470.44 \\
2.00 \\
\end{array}$ & & $1,470.44$ & 0.20 \\
\hline $\begin{array}{l}\text { OTROS FROGRAMAS SOCIALES } \\
\text { No. de proyectos }\end{array}$ & & & $\begin{array}{r}26,000.00 \\
1.00 \\
\end{array}$ & $26,000.00$ & 3.60 \\
\hline $\begin{array}{l}\text { SUBTOOTAL DE PROGRAMAS SOCIALES } \\
\text { No. de proyectos }\end{array}$ & $\begin{array}{r}134,873.86 \\
14.00\end{array}$ & $\begin{array}{r}293,376.62 \\
9.00\end{array}$ & $\begin{array}{r}65,400.00 \\
3.00 \\
\end{array}$ & $493,650.48$ & 68.37 \\
\hline $\begin{array}{l}\text { PROGRAMAS PUBLICOS NO SOCLALES } \\
\text { No. de proyectos }\end{array}$ & $\begin{array}{r}25,300.00 \\
5.00 \\
\end{array}$ & $\begin{array}{r}12,903.48 \\
4.00 \\
\end{array}$ & $\begin{array}{r}190,214.00 \\
5.00 \\
\end{array}$ & $228,417.48$ & 31.63 \\
\hline $\begin{array}{l}\text { TOTAL } \\
\text { No. de proyectos }\end{array}$ & $\begin{array}{r}160,173.90 \\
19.00 \\
\end{array}$ & $\begin{array}{r}306,280.10 \\
13.00 \\
\end{array}$ & $\begin{array}{r}255,614.00 \\
8.00 \\
\end{array}$ & $722,068.00$ & 100.00 \\
\hline $\begin{array}{l}\text { TOTAL } \\
\text { No. de Proyectos }\end{array}$ & $\begin{array}{r}174,277.90 \\
39.00\end{array}$ & $\begin{array}{r}1,789,254.40 \\
293.00\end{array}$ & $\begin{array}{r}535,163.00 \\
107.00\end{array}$ & $2,498,695.30$ & \\
\hline
\end{tabular}

FUENTE: OECD

CALCULOS: FEDESARROLLO 
Cuadro No. 8

EL SALVADOR: FLUJOS DE AYUDA EXTERNA AL SECTOR DE SERVICIOS

SOCIAIES Y COMUNITARIOS 1973-1992

POR DONANTE Y TTPO (MILES DE DOLARES)

\begin{tabular}{|c|c|c|c|c|c|}
\hline DONANTE/TIPO & $73-79$ & $80-89$ & $90-92$ & TOTAL & $\%$ \\
\hline \multicolumn{6}{|l|}{$\begin{array}{l}\text { BILATEXRA } \\
\text { ESTADOS UNIDOS } \\
\text { X्XU/AYUDA BILA } \mathbf{8 1 . 8 5}\end{array}$} \\
\hline $\begin{array}{l}\text { Formación bruta de capital } \\
\text { Numero de proyectos }\end{array}$ & $\begin{array}{r}9,850.00 \\
4.00 \\
\end{array}$ & $\begin{array}{r}702,799.00 \\
113.00 \\
\end{array}$ & $\begin{array}{r}132,216.00 \\
41.00 \\
\end{array}$ & $844,865.00$ & 52.93 \\
\hline $\begin{array}{l}\text { No formación bruta de capital } \\
\text { Numero de proyectos }\end{array}$ & i & $\begin{array}{r}79,128.00 \\
21.00 \\
\end{array}$ & $\begin{array}{r}17,193.00 \\
4.00 \\
\end{array}$ & $96,321.00$ & 6.03 \\
\hline $\begin{array}{l}\text { No asignable por sector } \\
\text { Numero de proyectos }\end{array}$ & $\begin{array}{r}1,025.00 \\
2.00 \\
\end{array}$ & $\begin{array}{r}552,037.00 \\
34.00 \\
\end{array}$ & $\begin{array}{r}102,077.00 \\
8.00 \\
\end{array}$ & $655,139.00$ & 41.04 \\
\hline Total & $\begin{array}{r}10,875.00 \\
6.00 \\
\end{array}$ & $\begin{array}{r}1,333,964.00 \\
168.00 \\
\end{array}$ & $\begin{array}{r}251,486.00 \\
53.00 \\
\end{array}$ & $1,596,325.00$ & 100.00 \\
\hline \multicolumn{6}{|l|}{$\begin{array}{l}\text { PAISESS NORDICOSY CANADA } \\
\text { PN Y CAN/AYU BIL S.23 }\end{array}$} \\
\hline $\begin{array}{l}\text { Formación bruta de capital } \\
\text { Numero de proyectos }\end{array}$ & $\begin{array}{r}2,667.50 \\
6.00\end{array}$ & $\begin{array}{r}7,982.20 \\
13.00\end{array}$ & $\begin{array}{r}5,513.30 \\
6.00\end{array}$ & $16,163.00$ & 28.16 \\
\hline $\begin{array}{l}\text { No formación bruta de capital } \\
\text { Numero de proyectos }\end{array}$ & $\begin{array}{r}33.20 \\
2.00 \\
\end{array}$ & $\begin{array}{r}24.90 \\
6.00 \\
\end{array}$ & $\begin{array}{r}2,389.10 \\
7.00\end{array}$ & $2,847.20$ & 4.96 \\
\hline $\begin{array}{l}\text { Cooperación Técnica } \\
\text { Numero de proyectos }\end{array}$ & $\begin{array}{r}42.70 \\
1.00 \\
\end{array}$ & $\begin{array}{r}612.80 \\
2.00 \\
\end{array}$ & $\begin{array}{r}1,116.30 \\
3.00 \\
\end{array}$ & $1,771.80$ & 3.09 \\
\hline $\begin{array}{l}\text { No asignable por sector } \\
\text { Numero de proyectos }\end{array}$ & $\begin{array}{r}279.10 \\
2.00 \\
\end{array}$ & $\begin{array}{r}31,906.10 \\
48.00 \\
\end{array}$ & $\begin{array}{r}4,427.90 \\
13.00 \\
\end{array}$ & $36,613.10$ & 63.79 \\
\hline Total & $\begin{array}{r}3,022.40 \\
11.00 \\
\end{array}$ & $\begin{array}{r}40,926.00 \\
69.00 \\
\end{array}$ & $\begin{array}{r}13,446.60 \\
29.00 \\
\end{array}$ & $57,395.00$ & 100.00 \\
\hline \multicolumn{6}{|c|}{$\begin{array}{l}\text { EUROPA CENTRAL Y OCCIDENTAL. } \\
\text { EC Y O/AYD BIL. } 5.99\end{array}$} \\
\hline $\begin{array}{l}\text { Formación bruta de capital } \\
\text { Numero de proyectos }\end{array}$ & $\begin{array}{r}166.40 \\
1.00\end{array}$ & $\begin{array}{r}65,149.80 \\
11.00 \\
\end{array}$ & $\begin{array}{r}8,342.10 \\
4.00 \\
\end{array}$ & $73,658.30$ & 69.26 \\
\hline $\begin{array}{l}\text { No formación bruta de capital } \\
\text { Numero de proyectos }\end{array}$ & & $\begin{array}{r}691.00 \\
1.00 \\
\end{array}$ & & 691.00 & 0.65 \\
\hline $\begin{array}{l}\text { Cooperación Técnica } \\
\text { Numero de proyectos }\end{array}$ & $\begin{array}{r}40.20 \\
2.00 \\
\end{array}$ & $\begin{array}{r}120.00 \\
1.00 \\
\end{array}$ & $\begin{array}{r}137.20 \\
2.00 \\
\end{array}$ & 297.40 & 0.28 \\
\hline $\begin{array}{l}\text { No asignable por sector } \\
\text { Numero de proyectos }\end{array}$ & & $\begin{array}{r}30,706.90 \\
23.00 \\
\end{array}$ & $\begin{array}{r}1,000.90 \\
5.00 \\
\end{array}$ & $31,707.80$ & 29.81 \\
\hline Total & $\begin{array}{r}206.60 \\
3.00\end{array}$ & $\begin{array}{r}96,667.70 \\
36.00 \\
\end{array}$ & $\begin{array}{r}9,480.10 \\
11.00\end{array}$ & $106,354.40$ & 100.00 \\
\hline
\end{tabular}


Cuadro No. 8 (Continusción)

EL SALVADOR: FLUJOS DE AYUDA EXTERNA AL SECTOR DE SERVICIOS

SOCIALES Y COMUNITARIOS 1973-1992

POR DONANTE Y TTPO (MILES DE DOLARES)

\begin{tabular}{|c|c|c|c|c|c|}
\hline DONANTE/TIPO & $73-79$ & $80-89$ & $90-92$ & TOTAL & $\%$ \\
\hline $\begin{array}{l}\text { APPON } \\
\text { JAPON/AYU BIL } 0.93\end{array}$ & & & & & \\
\hline $\begin{array}{l}\text { Formación bruta de capital } \\
\text { Numero de proyectos }\end{array}$ & & $\begin{array}{r}6,818.70 \\
3.00 \\
\end{array}$ & $\begin{array}{r}5,136.30 \\
6.00 \\
\end{array}$ & $11,955.00$ & 72.22 \\
\hline $\begin{array}{l}\text { No formación bruta de capita } \\
\text { Numero de proyectos }\end{array}$ & & & & & \\
\hline $\begin{array}{l}\text { No asignable por sector } \\
\text { Numero de proyectos }\end{array}$ & & $\begin{array}{r}4,597.90 \\
4.00 \\
\end{array}$ & & $4,597.90$ & 27.78 \\
\hline Total & $\begin{array}{l}0.00 \\
0.00 \\
\end{array}$ & $\begin{array}{r}11,416.60 \\
7.00 \\
\end{array}$ & $\begin{array}{r}5,136.30 \\
6.00 \\
\end{array}$ & $16,552.90$ & 100.00 \\
\hline $\begin{array}{l}\text { SUBTOTAL BILATERAL } \\
\text { AY BIL/AES } 71.10\end{array}$ & $\begin{array}{r}14,104.00 \\
20.00\end{array}$ & $\begin{array}{r}1,482,974.28 \\
280.00\end{array}$ & $\begin{array}{r}279,548.95 \\
99,00\end{array}$ & $1,776,627.23$ & \\
\hline Numero de proyectos & 39.00 & 293.00 & 107.00 & & \\
\hline
\end{tabular}

Fuente: OECD

Cálculos: FEDESARROLIO 
CUNDRO NO. 9

PAIS: EL SALVADOR

TEMA: AYUDA EXTENA POR TIFO DE FUJO, 1979-1992 (MILLONES DE DOLARES)

\begin{tabular}{|c|c|c|c|c|c|}
\hline ANO & Donecion & Cussi-done 1/ & Prest ODA $2 /$ & Aporlesp 3/ & Total \\
\hline 1973 & $1,469.00$ & $6,300.00$ & & & $7,969.00$ \\
\hline 1974 & 486.00 & $21,000.00$ & $19,500.00$ & & $40,986.00$ \\
\hline 1975 & $1,376.47$ & $62,191.92$ & & & $63,568.39$ \\
\hline 1976 & 61.91 & $24,000.00$ & & so,000.00 & $54,06 I .91$ \\
\hline 1977 & $1,115.01$ & $26,000.00$ & & $6,700.00$ & $33,815.01$ \\
\hline 1978 & $1,121.76$ & $61,101.99$ & & $77,000.00$ & $139,223.75$ \\
\hline 1979 & I, $\mathbf{B 6 2 . 7 5}$ & $25,320.44$ & & $39,800.00$ & $66,983.19$ \\
\hline 1980 & $3,090.85$ & $133,800.00$ & $1,500.00$ & & $138,990.85$ \\
\hline 1981 & $32,086.58$ & $120,780.00$ & & & $152,866.58$ \\
\hline 1982 & $118,844.87$ & $115,900.00$ & $89,900.00$ & & $324,244.87$ \\
\hline 1983 & $198,773.10$ & $101,500.00$ & & & $260,273.10$ \\
\hline 1984 & $197,985.19$ & $111,122.59$ & $65,641.00$ & & $314,748.78$ \\
\hline 1985 & $366,510.03$ & $96,697.00$ & $40,635.00$ & & $503,842.03$ \\
\hline 1986 & $282,130.73$ & $29,092.14$ & & & $511,582.87$ \\
\hline 1987 & 499,1 71.93 & $67,767.87$ & $70,600.00$ & & $571,599.80$ \\
\hline 1988 & $321,125.77$ & $266,811.65$ & & & $587,937,42$ \\
\hline 1989 & $306,930.01$ & $12,866.90$ & & & $319,196.91$ \\
\hline 1990 & $217,831.95$ & $89,600.00$ & & & $307,431.95$ \\
\hline 1991 & $197,874.83$ & $94,000.00$ & $152,000.00$ & & $443,874.83$ \\
\hline 1992 & $28,942.03$ & $65,000.00$ & $185,214.00$ & & $278,556.05$ \\
\hline TOTAL & $2,611,590.79$ & $1,531,012.50$ & $621,590.00$ & IsS,500.00 & $1,920,693.29$ \\
\hline PORC. & 59.07 & S1.II & 12.69 & 3.12 & $100 \%$ \\
\hline
\end{tabular}

FUENTE: ORCD

I/ SON JRESTAMOS EN DONDE POR LO MENOS EL 70\% DEL TOTAL SON DONADOS

2/ ASISTENCIA ORCIAL PARA QI DESARROWO

3/ OTROS APOKTES DEL SECTOR PUBLCO 
CUADRO No. 10

-PAS: EL SALVADOR

TEMA: SITUACION DE POBREZA 1980-1992

\begin{tabular}{|c|c|c|c|c|}
\hline CATEGORIAS & $\begin{array}{c}\text { CEPAL } \\
1980\end{array}$ & $\begin{array}{c}\text { CENITEC } \\
1985\end{array}$ & $\begin{array}{c}\text { MIPLAN } \\
1988\end{array}$ & $\begin{array}{l}\text {.MIPLAN } \\
1991-92 \\
\end{array}$ \\
\hline $\begin{array}{l}\text { Pobreza a nivel nacional } \\
\text { Pobreza extrema } \\
\text { Pobreza relativa } \\
\text { No pobres } \\
\text { Total }\end{array}$ & $\begin{array}{l}\text { Habitantes \% } \\
50.6 \\
17.3 \\
31.9 \\
100.0\end{array}$ & $\begin{array}{l}\text { Hogares } \% \\
64.1 \\
23.4 \\
12.5 \\
100.0\end{array}$ & Hogares $\%$ & $\begin{array}{l}\text { Hogares \% } \\
28.2 \\
31.5 \\
40.3 \\
100.0\end{array}$ \\
\hline $\begin{array}{l}\text { Pobreza a nivel urbano } \\
\text { Pobreza extrema } \\
\text { Pobreza relativa } \\
\text { No pobres } \\
\text { Total }\end{array}$ & $\begin{array}{l}44.5 \\
13.1 \\
42.4 \\
100.0\end{array}$ & $\begin{array}{l}50.0 \\
30.0 \\
20.0 \\
100.0\end{array}$ & $\begin{array}{l}23.6 \\
31.9 \\
44.5 \\
100.0\end{array}$ & $\begin{array}{l}23.3 \\
30.5 \\
46.2 \\
100.0\end{array}$ \\
\hline $\begin{array}{l}\text { Pobreza a nivel rural } \\
\text { Pobreza extrema } \\
\text { Pobreza relativa } \\
\text { No pobres } \\
\text { Total }\end{array}$ & $\begin{array}{l}55.4 \\
21.0 \\
23.6 \\
100.0\end{array}$ & $\begin{array}{c}80.0 \\
16.0 \\
4.0 \\
100.0\end{array}$ & & $\begin{array}{l}33.6 \\
32.5 \\
33.9 \\
100.0\end{array}$ \\
\hline
\end{tabular}

CEPAL 1980: Centroamerica: Indicadores Socioeconómicos para el Desarrollo FLACSO, San Jose 1983.

CENTIEC 1985: La Erradicación de la pobreza en El Salvador, Politica, Económica No. 4, 1991 .

MIPLAN 1988-1992: Encuesta de Hogares de Propósitos Múltiples Oct.1988-Feb.1989 y Oct. 1991-Feb. 1992 
CUADRO No. 11

PAIS: EL. SALVADOR

TEMA: INDICADORES SOCIALES 1970-1992

\begin{tabular}{|c|c|c|c|c|c|c|c|c|c|}
\hline \multirow{3}{*}{ Año } & \multicolumn{3}{|c|}{ Población } & \multirow{3}{*}{$\begin{array}{l}\text { Esperanza de } \\
\text { vida al nacer } \\
\text { (Años) }\end{array}$} & \multirow{3}{*}{$\begin{array}{c}\text { Mortalidad } \\
\text { Infantil x } 1000 \\
\text { Nacidos vivos }\end{array}$} & \multicolumn{2}{|c|}{ Analfabetismo } & \multirow{2}{*}{\multicolumn{2}{|c|}{$\begin{array}{l}\text { Matrícula Inicial } \\
\text { Educación (Miles) }\end{array}$}} \\
\hline & \multirow{2}{*}{$\begin{array}{l}\text { Total } \\
\text { miles }\end{array}$} & \multirow{2}{*}{$\begin{array}{c}\text { Rural } \\
\% \\
\end{array}$} & \multirow{2}{*}{\begin{tabular}{|c|}
$\begin{array}{c}\text { Urbana } \\
\%\end{array}$ \\
\end{tabular}} & & & \multirow{2}{*}{$\begin{array}{l}\text { Total } \\
\text { (\%) }\end{array}$} & \multirow{2}{*}{$\begin{array}{c}\text { Rural } \\
\%\end{array}$} & & \\
\hline & & & & & & & & Primaria & Secundaria \\
\hline 1970 & 3582 & 60.6 & 39.4 & 59.1 & 66.6 & 40.3 & 55.3 & 531 & 88 \\
\hline 1980 & 4797 & 55.8 & 44.2 & 62.2 & ip(78) & $33.1(78)$ & 46.1 & $823(77)$ & 65 \\
\hline 1992 & 5166 & 52.3 & 47.7 & 64.4 & 56.0 & $23^{\prime}$ & 34.1 & 1042 & 105 \\
\hline
\end{tabular}

\section{FUENTE:}

1970-80: Centroamerica: Indicadores socioeconómicos para el Desarrollo, FLACSO, San José, 1983.

MIPLAN, EHPM, 1991-92. 